\title{
Ecological guidelines for designing networks of marine reserves in the unique biophysical environment of the Gulf of California
}

\author{
Adrian Munguia-Vega ${ }^{(1)} \cdot$ Alison L. Green - Alvin N. Suarez-Castillo • \\ Maria Jose Espinosa-Romero - Octavio Aburto-Oropeza • Andrés M. Cisneros-Montemayor • \\ Gabriela Cruz-Piñón • Gustavo Danemann • Alfredo Giron-Nava • \\ Ollin Gonzalez-Cuellar • Cristina Lasch • Maria del Mar Mancha-Cisneros • \\ Silvio Guido Marinone • Marcia Moreno-Báez • Hem-Nalini Morzaria-Luna • \\ Héctor Reyes-Bonilla · Jorge Torre · Peggy Turk-Boyer • Mariana Walther • \\ Amy Hudson Weaver
}

Received: 7 November 2017/Accepted: 13 July 2018/Published online: 21 July 2018

(C) The Author(s) 2018

\begin{abstract}
No-take marine reserves can be powerful management tools, but only if they are well designed and effectively managed. We review how ecological guidelines for improving marine reserve design can be adapted based on an area's unique evolutionary, oceanic, and ecological characteristics in the Gulf of California, Mexico. We provide ecological guidelines
\end{abstract}

Electronic supplementary material The online version of this article (https://doi.org/10.1007/s11160-018-9529-y) contains supplementary material, which is available to authorized users.

A. Munguia-Vega $\cdot$ A. N. Suarez-Castillo .

M. J. Espinosa-Romero · J. Torre

Comunidad y Biodiversidad A.C., Guaymas, Sonora, Mexico

\footnotetext{
A. Munguia-Vega $(\square)$

Conservation Genetics Laboratory, School of Natural Resources and the Environment, The University of Arizona, Tucson, AZ, USA

e-mail: airdrian@email.arizona.edu
}

A. L. Green

The Nature Conservancy, Brisbane, QLD, Australia

O. Aburto-Oropeza · A. Giron-Nava · M. Moreno-Báez Marine Biology Research Division, Scripps Institution of Oceanography, University of California, San Diego,

La Jolla, CA, USA to maximize benefits for fisheries management, biodiversity conservation and climate change adaptation. These guidelines include: representing 30\% of each major habitat (and multiple examples of each) in marine reserves within each of three biogeographic subregions; protecting critical areas in the life cycle of focal species (spawning and nursery areas) and sites with unique biodiversity; and establishing reserves in areas where local threats can be managed effectively. Given that strong, asymmetric oceanic currents reverse direction twice a year, to maximize
A. M. Cisneros-Montemayor
Nippon Foundation Nereus Program, Institute for the
Oceans and Fisheries, University of British Columbia,
Vancouver, BC, Canada
G. Cruz-Piñón · H. Reyes-Bonilla
Departamento de Biología Marina, Universidad
Autónoma de Baja California Sur, La Paz,
Baja California Sur, Mexico
G. Danemann
Pronatura Noroeste A.C., Ensenada, Baja California, Mexico
O. Gonzalez-Cuellar · A. H. Weaver
Sociedad de Historia Natural Niparajá A.C., La Paz,
Baja California Sur, Mexico 
connectivity on an ecological time scale, reserves should be spaced less than 50-200 km apart depending on the planktonic larval duration of target species; and reserves should be located upstream of fishing sites, taking the reproductive timing of focal species in consideration. Reserves should be established for the long term, preferably permanently, since full recovery of all fisheries species is likely to take $>25$ years. Reserve size should be based on movement patterns of focal species, although marine reserves $>10 \mathrm{~km}$ long are likely to protect $\sim 80 \%$ of fish species. Since climate change will affect species' geographic range, larval duration, growth, reproduction, abundance, and distribution of key recruitment habitats, these guidelines may require further modifications to maintain ecosystem function in the future.

Keywords Biodiversity - Climate change · Connectivity · Conservation · Fisheries · Recovery rates

\section{Marine reserves and the Gulf of California}

Marine reserves (defined here as no-take zones or areas of the ocean that are fully protected from all extractive and destructive activities) can be effective management tools for enhancing fisheries, conserving biodiversity, and adapting to climate change (Green et al. 2014; Roberts et al. 2017). This is because marine reserves can increase the biomass, species and genetic diversity, and individual size, age and reproductive potential of many species (particularly

C. Lasch

The Nature Conservancy, Mérida, Yucatán, Mexico

M. del Mar Mancha-Cisneros

Ecology, Evolution and Environmental Sciences, School of Life Sciences, Arizona State University, Tempe, AZ, USA

S. G. Marinone

Departamento de Oceanografía Física, Centro de Investigación Científica y de Educación Superior de Ensenada, Ensenada, Baja California, Mexico

M. Moreno-Báez

Department of Environmental Studies, University of New England, Biddeford, ME, USA fisheries species) within their boundaries (Baskett and Barnett 2015; Gill et al. 2017), and export eggs, larvae and adults to support fisheries in adjacent areas (Green et al. 2015). However, the benefits of reserves are evident only if they are well designed, effectively managed and socially supported (Gill et al. 2017). For example, a recent global review showed that there were twice as many large ( $>250 \mathrm{~mm}$ total length) fish species, five times more biomass of large fish, and 14 times more shark biomass, in marine reserves if they were enforced, long-term ( $>10$ years), large $\left(>100 \mathrm{~km}^{2}\right)$ and isolated by deep-water or sand (Edgar et al. 2014).

One of the first steps in the marine reserve design process is to clearly define ecological and socioeconomic guidelines where: ecological guidelines aim to maximize biological objectives by taking ecological and physical processes into account; and socioeconomic guidelines aim to maximise benefits and minimise costs to local communities and other stakeholders (e.g. Fernandes et al. 2005; Green et al. 2009).

A long history of providing ecological guidelines for the design of marine reserves exists. Initially, these guidelines were focused on selecting candidate sites based on maximum biodiversity protection (e.g. regarding biogeographic representation, habitat representation and heterogeneity, and the presence of species or populations of special interest i.e. threatened species) or ensuring the sustainability of biodiversity and fishery values (e.g. regarding reserve sizes needed to protect viable habitats, the presence of focal species through their life cycle, connectivity among reserves and links among ecosystems) while avoiding human and natural threats (Roberts et al. 2003). Later

H. Morzaria-Luna · P. Turk-Boyer

Centro Intercultural de Estudio de Desiertos y Oceános

A.C., Puerto Peñasco, Sonora, Mexico

H. Morzaria-Luna

Northwest Fisheries Science Center, NOAA, Seattle, WA, USA

M. Walther

The Nature Conservancy, La Paz, Baja California Sur, Mexico 
versions emphasized the need to design networks of multiple interconnected reserves to scale up their benefits and allow for multiplicative properties that are not present in individual reserves (e.g. the demographic coupling of populations in different reserves: Gaines et al. 2010; Sale et al. 2010; Jessen et al. 2011), or to more carefully consider constraints imposed by local human activities (Fraschetti et al. 2009).

Although recommendations for marine reserve design may differ if the goal is biodiversity conservation or fisheries enhancement (e.g. see Roberts et al. 2003), some studies have demonstrated how to reduce or eliminate tradeoffs to achieve these goals simultaneously (Gaines et al. 2010; Green et al. 2014). More recently, ecological guidelines have focused on designing marine reserves to mitigate for, or promote adaption to, climate change (Jessen et al. 2011; Brock et al. 2012; McLeod et al. 2012; Green et al. 2014; Roberts et al. 2017).

Ecological guidelines have been established for some tropical marine (Abesamis et al. 2014; Green et al. 2014, 2015) and temperate ecosystems (e.g. in Canada or California: Airame et al. 2003; Jessen et al. 2011; Saarman et al. 2013), but are lacking for other biophysical environments. In this study, we demonstrate how ecological guidelines for marine reserve design can be adapted and refined based on an area's unique evolutionary, oceanic, and ecological characteristics in the Gulf of California (GOC), Mexico. These guidelines will be used to design networks of marine reserves to maximize the benefits for fisheries management, biodiversity conservation, and climate change adaptation throughout the GOC.

In 2002, Sala et al. (2002) used an innovative approach to design a network of marine reserves to protect biodiversity and complement fisheries management in reef habitats in the GOC, focusing mainly along the coast of Baja California Sur (which included $44 \%$ of the Gulf's reef habitats). Sala et al. (2002) used optimization algorithms with information regarding biodiversity, ecological processes and socioeconomic factors (fishing pressure). Here we expand on and refine this approach by: considering the entire GOC; incorporating new scientific information (e.g. on patterns of biodiversity and larval dispersal); using new approaches for marine reserve design that consider movement patterns and recovery times of focal species, and adapting to climate change (Abesamis et al. 2014; Green et al. 2014, 2015); and collecting new information required to optimize the application of marine reserve design tools such as Marxan (Beger et al. 2015).

\section{Study area}

The Gulf of California (GOC: Fig. 1) has been widely recognized as a marine biodiversity hotspot (Roberts et al. 2002). Nearly 6000 macroscopic marine animal species have been described (4854 invertebrates and 1115 vertebrates including 801 teleosts and 87 elasmobranchs), of which about $16 \%$ are endemic to the GOC (Brusca et al. 2005), making it one of the world's top 10 ecosystems for endemic species (Roberts et al. 2002). The GOC is a unique geological and oceanic system due to the rifting of the Baja California Peninsula away from mainland Mexico over the last 12 million years (Dolby et al. 2015). This has created a long $(+1500 \mathrm{~km})$, narrow $(\sim 100 \mathrm{~km})$ and deep $(+4 \mathrm{~km})$ body of water that covers $\sim 270,000 \mathrm{~km}^{2}$. Oceanographically, the GOC is characterized by a series of gyres that consistently reverse directions twice a year (Marinone et al. 2011; Marinone 2012). Strong tidal mixing and wind-driven coastal upwelling result in high year-round primary productivity (Lavin and Marinone 2003) with 700,000 tons of seafood produced annually (Paez-Osuna et al. 2016) including $\sim 40 \%$ bycatch (Cisneros-Montemayor et al. 2013). This production represents $40-77 \%$ of the volume of Mexico's fisheries and about $50 \%$ of its value (330 million USD in 2014). The GOC supports at least half of nation's fisheries-related jobs (a conservative estimate of $\sim 32,600$ ), with an estimated 937 large and $>12,500$ small fishing vessels (pangas) in operation (Paez-Osuna et al. 2016). Marine ecotourism in the GOC is another important economic activity, attracting $\sim 900,000$ people every year who spend over 500 million USD (Spalding et al. 2016).

The GOC is currently at a crossroads between over exploitation of marine resources and rapid biodiversity loss (Sala et al. 2004; Sagarin et al. 2008), and concerted efforts to preserve and restore biodiversity (Carvajal et al. 2010; Alvarez-Romero et al. 2013). For example, it is estimated that $85 \%$ of GOC fisheries are either at their maximum sustainable yield or overexploited (Cisneros-Mata 2010), and there are twice as many pangas than needed to land the theoretical maximum fish biomass (Johnson et al. 2017). Currently, only 7\% of the GOC is under 


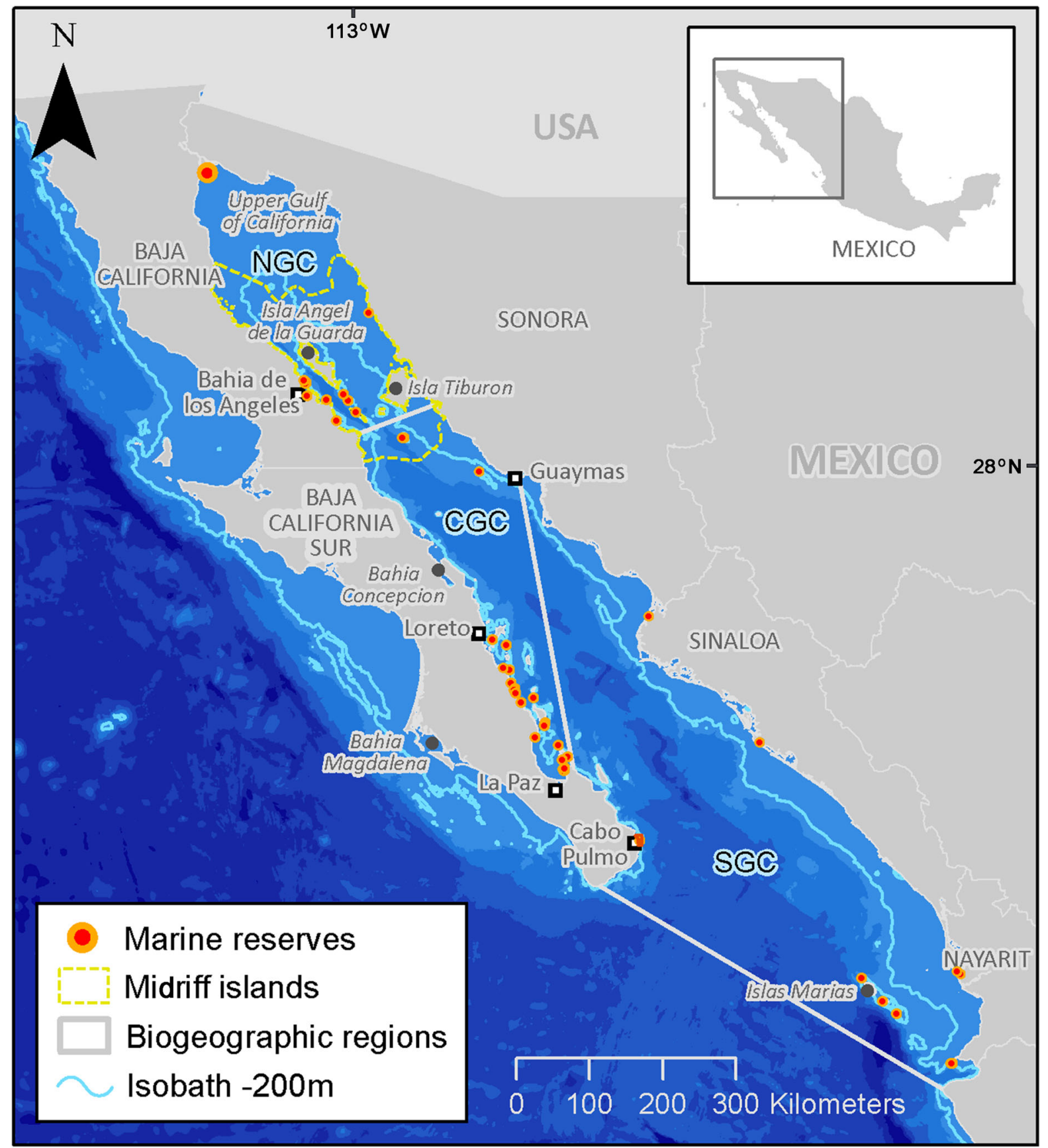

Fig. 1 Gulf of California showing the location of 47 existing marine reserves, and the location of the three biogeographic subregions (Brusca et al. 2005): Northern (NGC), Central (CGC) and Southern (SGC). Note the sizes of the marine

some form of protection in Marine Protected Areas (MPAs, clearly defined geographical spaces, dedicated and managed, through legal or other effective reserves are not shown to scale. For estimates of the size of each reserve and detailed maps showing their location, see Online Resource 1. The location of the Midriff islands region is shown, a region of large islands mentioned in the text

means, to achieve the long-term conservation of nature and associated ecosystem services and cultural values: Dudley 2008). 
MPAs may include marine reserves, but they can also contain other management zones. Currently, marine reserves represent less than $0.5 \%$ of the GOC and are located within 16 MPAs administered by two distinct governmental agencies (Online Resource 1). Together they include 47 individual marine reserves that are heavily clustered, leaving large areas of ocean without reserves in-between (Fig. 1). The second oldest and largest of these marine reserves, Cabo Pulmo National Park established in 1995, is the only one that shows strong signs of recovery in biomass and size structure of multiple species (Aburto-Oropeza et al. 2011). This is probably because most of the other reserves were either not well designed (e.g. too small), are too recent, or have not been effectively managed (e.g. due to a lack of enforcement and community involvement: Rife et al. 2013) (See Edgar et al. 2014).

\section{Ecological guidelines for marine reserve design in the Gulf of California}

We provide 19 ecological guidelines for designing a network of marine reserves to enhance fisheries, conserve biodiversity and adapt to climate change in the GOC (Table 1). The analysis is based on consultations with leading scientists and managers (Online Resource 2) who work in the region through a series of workshops and the formation of working groups from 2015 to 2017. Experts included researchers from academic institutions in Mexico, Australia and the USA, representatives from fisheries and environmental agencies within the Mexican government and multiple civil society organizations based in Mexico (NGOs). Participants reviewed the scientific rationale for ecological guidelines developed elsewhere and adapted these guidelines to the unique evolutionary, oceanic and ecological characteristics of the GOC by using the best available scientific information.

These guidelines address six major categories: habitat representation and replication; protecting critical and unique areas; incorporating connectivity; allowing time for recovery; considering threats and opportunities; and climate change adaptation (see Table 1). We provide the scientific rationale for each guideline, explain how it relates to the unique biophysical environment in the GOC, and summarize key considerations for applying each guideline in the design process (see Table 1). Many of these guidelines address the ecological needs of focal species, which include key fisheries species, functional groups (e.g. herbivores) important for maintaining ecological resilience to local and global threats, and rare and threatened species. These guidelines were also developed specifically for designing networks of marine reserves for shallow water ecosystems and special and unique deep-water benthic habitats (i.e. seamounts, hydrothermal vents), where shallow water habitats are defined as those in $<200 \mathrm{~m}$ depth (which is often used as a proxy for the edge of the continental shelf where there is a dramatic ecotone between shallow and deep water habitats) (Spalding et al. 2007). These guidelines were not developed to apply to deep-water oceanic or pelagic habitats that tend to be spatially and temporally variable, and which may be managed more effectively using other management tools.

Habitat representation and replication

\section{Representation}

The GOC comprises a variety of habitats that vary along broad latitudinal and bathymetric gradients covering over 12 degrees in latitude. Based on community structure and the distribution of marine biota, three distinct biogeographic subregions (Northern, Central, Southern, Fig. 1) have been described where the same habitat supports distinct suites of species (Brusca et al. 2005; Brusca and Hendrickx 2010). Major habitat types in decreasing order of their coverage in the GOC include rocky reefs, wetlands, mangrove forests, Sargassum spp. forests, seagrass beds, rhodolith beds and seamounts, and their geographic distribution varies considerably among subregions (Fig. 2, see Online Resource 3 for detailed descriptions of each habitat). Sandy bottoms are also a major habitat type in the GOC, but their distribution and coverage remains unclear (see "Future research priorities" section).

Different species use different habitats, and many species move between habitats throughout their life cycle in the GOC (Aburto-Oropeza et al. 2007, 2009). Species composition (and relative abundance of species) varies within these habitats with depth, substrate, exposure, temperature and salinity, among other factors. Therefore, it is necessary to establish marine reserves that cover representative examples of each major habitat type to protect the full range of 
Table 1 Ecological guidelines and key considerations for using them to design networks of marine reserves in the Gulf of California

Ecological guidelines

Habitat representation and replication

1. Protect $30 \%$ of each major habitat type in marine reserves within each biogeographic subregion. If fisheries management is improved outside reserves, a lower level (but not $<10 \%$ ) could be used in the future

2. Protect at least three widely distributed examples of each major habitat type within each biogeographic subregion

Protecting critical and unique areas

3. Protect critical areas in the life history of focal species in marine reserves

4. Protect areas with unique biodiversity in marine reserves

\section{Incorporating connectivity}

5. Consider movement patterns of adults and juveniles of focal species when determining marine reserve size, where reserves should be more than twice the size of the home range of these species. Where focal species move long distances (10s-100s$1000 \mathrm{~s} \mathrm{~km}$ ), they may need to be managed using other management tools

6. Protect all key habitats used by focal species throughout their lives within individual marine reserves, or ensure that reserves are close enough to allow focal species to move among protected habitats within reserves

7. Use compact marine reserve shapes (e.g. squares or circles), except when protecting naturally elongated habitats (e.g. long narrow reefs)

8. Include whole ecological units in marine reserves

9. Locate more reserves in areas where there are high levels of larval retention or in upstream areas relative to the direction of the predominant flow, considering the seasonality of oceanic currents and spawning times of focal species

10. Space marine reserves less than 50-200 km apart in the direction of the predominant current flow during spawning time

\section{Allowing time for recovery}

11. Establish marine reserves for $>25$ years, preferably permanently, to allow populations of focal species to recover and enhance fisheries production in adjacent areas in the long term

12. Shorter term marine reserves should only be used in addition to, rather than instead of, long term or permanent reserves
Key considerations for application

Major habitat types for protection include: rocky reefs, seaweed forests (Sargassum spp., rhodoliths), mangrove forests, seagrass beds, wetlands (estuaries, saltmarsh), sandy bottoms and seamounts

The three biogeographic sub-regions are: Northern, Central and Southern GOC (Fig. 1)

Critical and unique areas include: fish spawning aggregations; nursery areas with marine vegetation (mangroves, Sargassum spp. and rhodoliths) for commercially important and protected species of fish and invertebrates; critical habitats (e.g. breeding, feeding and migratory pathways) for rare and threatened species (i.e. sea lions, cetaceans and sharks); biodiversity hotspots; habitats of endemic species, habitats with special and unique biodiversity (e.g. hydrothermal vents, intertidal beach rock "coquina" habitat, black coral forests and coral reefs); and coastal habitats around islands and islets

Most ( $\sim 80 \%)$ common and commercially important fish species with maximum individual length $<167 \mathrm{~cm}$ are likely to be protected within marine reserves with a minimum length of $10 \mathrm{~km}\left(100 \mathrm{~km}^{2}\right)$. Many $(\sim 70 \%)$ of these species may also be protected by reserves with a minimum linear extension of $5 \mathrm{~km}$. Larger reserves will be required for larger species

Many focal species use different habitats throughout their lives e.g. many use habitats with marine vegetation (mangroves, Sargassum spp. and rhodoliths) as nursery areas, while adults are mainly associated with rocky reefs

Whole ecological units may include offshore reefs or seagrass beds

Strong oceanic currents flow in different directions in different seasons (spring-summer vs. fall-winter)

Different species spawn in different seasons (most commercially important species spawn during spring and/or summer)

Mean larval dispersal distances for focal species tend to be between 50 and $200 \mathrm{~km}$ although they vary with PLD, habitat and location

Geographic distance is a poor predictor of larval connectivity compared to oceanographic distance that follows the direction of the predominant current flow

Populations of some trophic groups of reef fishes (herbivores and planktivores) are likely to take 8-11 years, respectively, to recover to $95 \%$ of their full carrying capacity after fishing ceases, while others (carnivores and piscivores) are likely to take 22-24 years 
Table 1 continued

Ecological guidelines

Considering threats and opportunities

13. Avoid establishing marine reserves in areas with threats to marine ecosystems that cannot be controlled within the reserve (e.g. land-based run-off)

14. Establish marine reserves in areas with lower levels of threats

15. Consider the cumulative effects of multiple threats in each location (e.g. high human population density, land-based runoff and climate change)

\section{Climate change adaptation}

16. Prioritize areas for protection where habitats and species are likely to be more resistant or resilient to climate change

17. Consider climate change effects on larval dispersal and implications for the location, number and spacing of reserves

18. Consider the effects of climate change on the distribution, growth, reproduction and recovery rates of species and implication for the duration and location of marine reserves

19. Consider the effects of climate change on ecosystem function and dynamics (e.g. changes in relative biomass of trophic groups, and changes due to variations in nutrient recycling/ upwelling), and implications for guidelines regarding habitat representation and replication, protecting critical, special and unique areas, and allowing time for recovery (see above)
Key considerations for application

The area around the Midriff Islands in the Northern GOC shows less cumulative human impacts compared to other areas in the Northern, Central and Southern GOC

The western coast (i.e. the Baja California peninsula) has lower levels of land-based threats (except for the northern and southern tips of the peninsula) than elsewhere in the GOC

Fishing impacts are highest in the Northern GOC and along the eastern (mainland) GOC coast

The effects of changes in climate and ocean chemistry (increased sea temperature, ocean acidification and sea level), and the resilience of marine habitats and species to these changes will vary regionally within the GOC

Fisheries production will likely decrease, due to similar effects observed during ENSO events

Climate change will likely reduce the biomass of some trophic or taxonomic groups and restructure food webs

Climate change will likely affect biological interactions between species through changes in their distribution, life history and connectivity

Some species ranges may contract or shift to the Northern GOC and the Pacific coast of Baja California

Where focal species include key fisheries species, functional groups important for maintaining ecological resilience to local and global threats and rare and threatened species. The numbers are used for ease of referencing only, and do not reflect order of priority

biodiversity and focal fisheries species (Fernandes et al. 2005; Green et al. 2014). But how much of each habitat type should be protected? It is generally considered that populations can only be maintained if they produce enough eggs and larvae to sustain themselves (Botsford et al. 2001, 2009). However, this threshold is unknown for most marine populations. Therefore, fisheries ecologists have expressed this threshold as a fraction of unfished stock levels, and meta-analyses suggest that keeping this threshold above $\sim 35 \%$ of unfished stock levels ensures adequate replacement for a range of species (Botsford et al. 2001; Fogarty and Botsford 2007).

This approach can be applied to marine reserve design, by using percent habitat protection as a proxy for protecting a similar proportion of fisheries stocks (reviewed in Green et al. 2014). It is also necessary to consider both fishing pressure and how well fisheries are managed outside marine reserves. For example, in areas where fishing pressure is low or fisheries are well managed outside marine reserves, lower levels of habitat protection in marine reserves (but not less than 10\%: Botsford et al. 2001, 2009) may be sufficient to ensure that an adequate proportion of the populations of focal species are protected overall (Green et al. 2014). In contrast, in areas where fishing pressure is high and fisheries management tools have been insufficient, $\sim 35 \%$ of the habitats used by focal species may need to be protected in marine reserves to ensure population maintenance (Fogarty and Botsford 2007). Higher levels of protection (40\%) are also recommended where fishing pressure is high on species with lower reproductive output or delayed maturation (e.g. sharks and some groupers: Fogarty and Botsford 2007).

Given that fishing pressure is high (Cisneros-Mata 2010; Johnson et al. 2017) and current fisheries management tools have not been sufficient (Rife et al. 2013), marine reserves in the GOC should include $30 \%$ of each major habitat type within each 


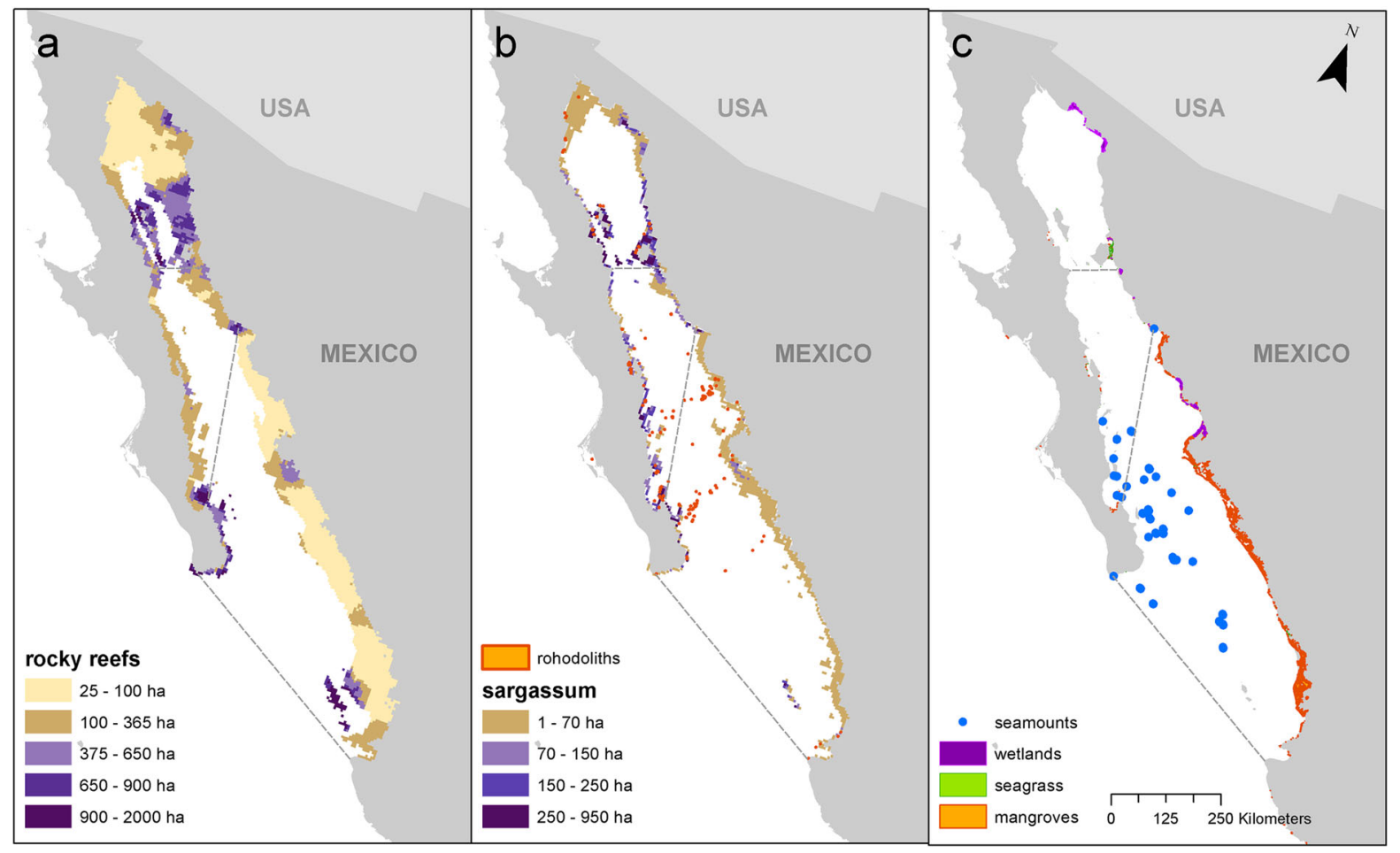

Fig. 2 Major habitats in the Gulf of California. a rocky reefs (including pebbles, shallow and deep reefs; $\mathbf{b}$ seaweed forests including Sargassum spp. and rhodoliths; c seamounts,

biogeographic subregion to allow for population maintenance of focal species (Table 1, Guideline 1). A lower level (but not less than 10\%) could be used in the future if fisheries management improves significantly outside reserves.

\section{Replication}

Large-scale disturbances (e.g. hurricanes, coral bleaching, disease outbreaks, land-based run-off triggered by hurricanes and harmful algal blooms) can have serious impacts on marine ecosystems in the GOC (Reyes-Bonilla et al. 2002; Alvarez-Romero et al. 2015; Paez-Osuna et al. 2016). Since it is not possible to predict which areas are most likely to be affected by these disturbances, we recommend that at least three examples of each major habitat should be protected within marine reserves in each of the three biogeographic subregions. We also recommend that these reserves should be widely distributed within each subregion to reduce the risk that all three areas will all be adversely affected by the same disturbance wetlands, seagrass beds and mangrove forests. See Online Resource 3 for details. Lines show the location of the three biogeographic subregions

at the same time (McLeod et al. 2009; Green et al. 2014) (Table 1, Guideline 2).

Therefore, if one example of a habitat type is severely damaged, larvae or propagules from the other reserves can help replenish the affected area. Habitat replication can also help ensure that variations in communities and species within habitat types are represented within the marine reserve network (McLeod et al. 2009; Gaines et al. 2010; Green et al. 2014).

Protecting critical and unique areas

\section{Critical areas in the life history of focal species}

Some focal fisheries species use different areas throughout their life cycle that are critically important for maintaining their populations, and protecting these areas can yield significant benefits for fisheries and biodiversity conservation (Table 1, Guideline 3). For example, fish spawning aggregations (FSAs) are transient aggregations of a large number of individuals 
from the same species, that gather specifically for the purpose of spawning (Erisman et al. 2017). FSAs are predictable in time and space due to geomorphology and ocean dynamics, and create complex, localized and ephemeral trophic relations that also attract top predators and megaplanktivores (Erisman et al. 2017). FSAs also concentrate reproductively active fish in a manner that makes them particularly vulnerable to fishing (Sadovy and Erisman 2012). In the GOC, FSAs usually take place during spring and summer (Erisman et al. 2010, 2012).

Because of the high reproductive potential concentrated in FSAs, especially those used by multiple species (Sadovy and Erisman 2012), these areas are critical for maintaining or restoring populations of focal species in the GOC (e.g. Lutjanidae: Lutjanus peru, L. argentiventris; Serranidae: Mycteroperca rosacea, Paralabrax aurogutattus, Paranthias colonus; Balistidae: Balistes polylepis). If the temporal and spatial locations of FSAs are known, as is the case for a few FSAs in the GOC (Sala et al. 2002, 2003; Erisman et al. 2012), they should be protected in permanent or seasonal marine reserves (Gaines et al. 2010). When the location of FSAs is unknown, or if focal species undertake long distance spawning migrations that are too large to include in individual reserves, FSAs can be protected within a network of reserves combined with other management approaches (e.g. seasonal closures and sales restrictions during spawning seasons) (Sadovy and Erisman 2012; Green et al. 2014, 2015).

Nursery grounds are also critical areas in the life cycle of focal fisheries species (Green et al. 2015). In the GOC, habitats with marine vegetation (Fig. 2), such as mangroves (Aburto-Oropeza et al. 2008, 2009), Sargassum spp. forests and rhodolith beds (Aburto-Oropeza et al. 2007; Hinojosa-Arango et al. 2014; Suarez-Castillo et al. 2014) provide important nursery areas for some focal fisheries species of fish (e.g. L. argentiventris, M. rosacea) and invertebrates that are under special protection by Mexican law (e.g. Pteria sterna, Pinctada mazatlanica, Spondylus limbatus, Isostichopus fuscus).

\section{Areas with unique biodiversity}

Some areas support unique biodiversity, which needs to be protected within permanent or seasonal marine reserves to protect all examples of biodiversity and ecosystem processes (Green et al. 2014). This includes areas used by rare and threatened species, and biodiversity hotspots with exceptional species diversity or endemicity (Table 1, Guideline 4). Where some species move long distances (e.g. large sharks and cetaceans), reserves may need to be combined with other management approaches, such as restrictions on the use of nets or boats (Cubero-Pardo et al. 2011).

In the GOC, there are $\sim 80$ large islands (Fig. 1) and more than 800 islets (Online Resource 4). These islands and islets in the GOC provide unique habitats for focal species and have been protected since 1986 . However, the protected areas do not include marine habitats deeper than the intertidal zone, and additional marine reserves may be required surrounding these islands to protect areas with unique and high levels of biodiversity (e.g. seabird and sea lion colonies). In the GOC, some unique habitats also include species or habitats that are rare and restricted to a few specific locations such as areas where cetaceans and sharks aggregate to feed such as seamounts, and rare habitats with unique species assemblages considered biodiversity hotspots including shallow hydrothermal vents, intertidal beach rock coquina habitats, coral reefs and black coral forests (see Online Resource 4 for detailed descriptions and a map with the location of these habitats). Coral reefs include Cabo Pulmo National Park, the northernmost coral reef in the Eastern Pacific Ocean (Fig. 1).

Other biological hotspots are areas with high levels of species diversity and endemism (Green et al. 2014). Many indicators have been used to measure biodiversity, including species richness, species overlap, presence of rare, keystone, endemic, or threatened species, and areas of increased productivity (Hooker et al. 2011). In the GOC, several assessments have identified biodiversity hotspots for marine conservation, mainly focused on selected endemic, endangered or protected taxa (e.g. sea turtles, marine mammals, seabirds) or particular taxonomic assemblages (e.g. reef fishes, invertebrates: Alvarez-Romero et al. 2013). We used a novel approach to model patterns of species richness in the GOC based on 286,533 occurrence records belonging to 12,098 species of marine plants, animals and microorganisms retrieved from online databases and published information (Morzaria-Luna et al. unpubl. data: see Online Resource 5). Using geometric interpolation (Raedig et al. 2010), the species richness model developed 
indicates that the Central GOC and the northern portion of the Southern GOC hold the highest levels of overall species diversity (Fig. 3). This result agrees with latitudinal gradients found for marine invertebrates based on recent underwater surveys (Ulate et al. 2016). Lower species diversity is found in the Northern GOC, probably related to its oceanographic isolation and colder winter temperatures that limit the survival of tropical species (Hastings et al. 2010).

The marine ecosystems of the GOC also have high levels of endemism (Brusca et al. 2005) due to their relative isolation and geologic evolution, high habitat heterogeneity driven by tides, currents, seasonal thermodynamics, high primary production (Lavin and Marinone 2003) and complex food webs (Ainsworth et al. 2011). Fish endemism in the GOC is estimated at $10 \%$ (Brusca et al. 2005). Invertebrate

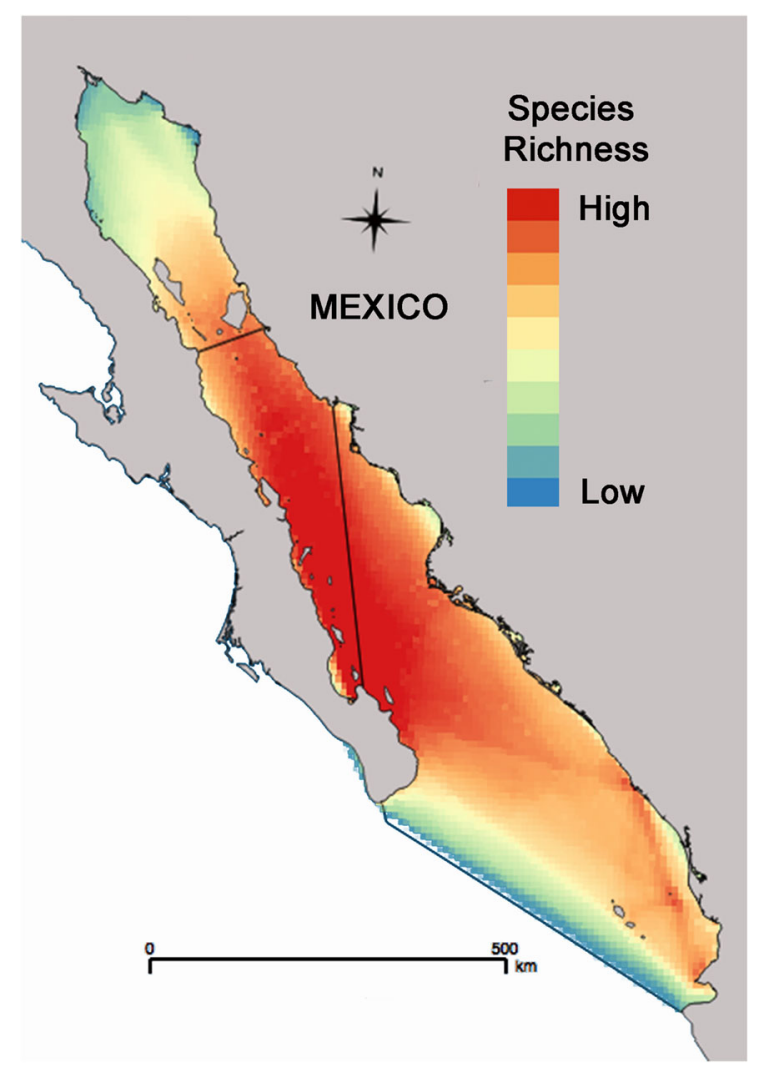

Fig. 3 Species richness in the Gulf of California estimated using an interpolation model based on 286,533 empirical records of 12,098 species of marine plants, animals and microorganisms (Morzaria-Luna et al. unpubl. data: see Online Resource 5 for details). Lines show the location of the three biogeographic subregions endemism, for example, at the phylum level ranges from $21 \%$ (Mollusca), 25\% (Echiura), $41 \%$ (Platelmintes), 50\% (Ctenophora) to $80 \%$ (Brachiopoda), with an average $\sim 16 \%$ for all invertebrate taxa combined (at least 766 endemic invertebrate species), although these figures should be used with caution given that some taxa have been poorly studied (Brusca et al. 2005). Several areas in the GOC are also considered as centers of endemism, including island systems such as Islas Marias and rocky reefs in the Midriff Islands (Fig. 1), coral reefs in the Southern GOC (Online Resource 4) (Roberts et al. 2002), and benthic habitats in the Central GOC that have high invertebrate endemicity (Brusca and Hendrickx 2010).

Incorporating connectivity

Connectivity (the demographic linking of local populations through the dispersal of individuals as adults, juveniles or larvae) has important implications for the persistence of metapopulations and their recovery from disturbance (Botsford et al. 2003; Green et al. 2015). Excluding strictly planktonic species (e.g. zooplankton) and fish without a larval stage (e.g. elasmobranchs), many invertebrates and fish have a bipartite life cycle where the larvae are pelagic before settling out of the plankton and spending the rest of their lives closely associated with the benthos. Species vary greatly in how far they move during each life history stage (Palumbi 2004), although larvae of most species tend to move longer distances (10s-100s of kilometers) than adults and juveniles which tend to be more sedentary (see review in Green et al. 2015). Some exceptions include species where adults and juveniles exhibit long distance (10s-100s km) ontogenetic habitat shifts (where juveniles use different habitats than adults) or transient spawning migrations (where adults move long distances from their home ranges to spawn), and pelagic species that move over very large distances (100s-1000s of kilometers) (Green et al. 2014, 2015).

When adults and juveniles leave a marine reserve, they become vulnerable to fishing pressure (Gaines et al. 2010). However, larvae leaving a reserve can generally disperse without elevated risk because of their small size and limited exposure to the fishery (Gaines et al. 2010). Therefore movement patterns of focal species at each stage of their life history are an important factor to consider in designing networks of 
marine reserves that enhance fisheries in adjacent areas (Botsford et al. 2003; Palumbi 2004).

\section{Movement of adults and juveniles}

For marine reserves to be effective management tools, they must be large enough to sustain focal species within their boundaries during their juvenile and adult life history phases (Gaines et al. 2010; Green et al. 2015). This will ensure that individuals can grow to maturity, increase in biomass and reproductive potential, and contribute more to stock recruitment and regeneration in fished areas through larval dispersal and spillover of adults and juveniles (Green et al. 2014, 2015). However, while spillover can directly benefit fisheries in adjacent areas, if the reserve is too small, excess spillover may reduce the protected biomass inside the reserve (Botsford et al. 2003; Gaines et al. 2010; Green et al. 2015).

Therefore, movement patterns of focal species should be used to refine marine reserve size (Table 1, Guideline 5). Movement patterns vary among and within species depending on several factors including size, sex, behavior, density, habitat characteristics, season, tide and time of day (Green et al. 2015). Some species like angelfishes and damselfishes tend to move small distances $(<0.1-0.5 \mathrm{~km})$, others including some parrotfishes and surgeonfishes move 3-10 km, while some groupers, snappers and jacks move tens to hundreds of kilometers and some sharks and large pelagic fishes move hundreds or even thousands of kilometers (Green et al. 2015). Some reef fishes (e.g. groupers and snappers) also travel long distances (10s-100s $\mathrm{km})$ to reach specific FSAs or to undergo ontogenetic shifts in habitat use (reviewed in Green et al. 2015).

Green et al. (2015) used this information to recommend minimum marine reserve sizes for these species based on their home range movement patterns, while noting that ideally this movement information should be combined with knowledge of how individuals are distributed to determine how many individuals a marine reserve of a specific size will protect. However, until such information becomes available, they recommended that marine reserves should be more than twice the size of the home range of focal species for protection (Table 1, Guideline 5). Green et al. (2015) also noted that these minimum reserve size recommendations must be applied to the specific habitats that the focal species use (in all directions), rather than the overall size of the reserve.

To apply this methodology in the GOC, we would need empirical measurements of the home range of adult and juvenile fishes and invertebrates, which are almost non-existent. Therefore, we used a novel approach based on the positive relationship between fish body size and movement patterns (Palumbi 2004), that used maximum individual length to predict the recommended minimum marine reserve size provided in Green et al. (2015). Our database included 147 species from 19 families of bony fishes (from Green et al. 2015), including only families that are present in the GOC (Online Resource 6). The power linear model found $\left(\mathrm{y}=0.003 \mathrm{x}^{1.5858}\right)$ explained $60 \%$ of the variance and was significant $(P<0.01)$. Therefore, we used the model based on maximum individual length to predict the recommended minimum marine reserve size for 123 common reef fish species in the GOC (including 75 commercial species: see Online Resource 6 for details). Our model indicates that reserves with a minimum length of $10 \mathrm{~km}$ (i.e. $10 \mathrm{~km} \times 10 \mathrm{~km}$, or $100 \mathrm{~km}^{2}$ ) are likely to protect $\sim 83 \%$ of the 123 species (and $81 \%$ of the 75 commercially important species) with maximum individual total lengths $<167 \mathrm{~cm}$ (Fig. 4, Online Resource 6). Even reserves with a minimum linear dimension of $5 \mathrm{~km}$ are likely to protect about $72 \%$ of the species considered in our analysis, including $67 \%$ of the commercial species (e.g. maximum individual length $<108 \mathrm{~cm}$ ). However, a $5 \mathrm{~km}$-wide reserve could exclude some species also important for artisanal fisheries that reach over $108 \mathrm{~cm}$ in length, which would need $10 \mathrm{~km}$-wide reserves (Fig. 4), including Hyporthodus acanthistius, Lutjanus novemfasciatus, Scomberomorus sierra, Seriola rivoliana and species of small sharks. In contrast, some species $167-250 \mathrm{~cm}$ in maximum total length might need even larger reserves (between 10 and $20 \mathrm{~km}$ minimum linear extension, Fig. 4) and other larger species not included in our analysis may require reserves 100 s or 1000s of km across (e.g. large sharks and billfishes).

Based on the results of our model, it appears that most current marine reserves in the GOC are too small to protect most fish species. For example, after excluding the largest marine reserve, the Alto Golfo de California y Delta del Río Colorado Biosphere Reserve as an outlier (area $882.5 \mathrm{~km}^{2}$, maximum marine reserve length $63.05 \mathrm{~km}$ ), the other 46 reserves 
in the GOC have an average area of $8.06 \mathrm{~km}^{2}(95 \%$ C.I. 3.17-12.95) and an average maximum linear length of only $2.69 \mathrm{~km}$ (95\% C.I. 1.82-3.57), with many $<1 \mathrm{~km}$ across (Online Resource 1). Therefore, our model predicts that existing reserves in the GOC will protect on average about $50 \%$ of all the fish species and $40 \%$ of the commercial species included in our analyses.

In contrast, in Cabo Pulmo National Park, most species within all trophic groups have shown strong signs of recovery in the largest reserve (maximum linear dimension of $9.16 \mathrm{~km}$ and an area of $21.78 \mathrm{~km}^{2}$ ) (Aburto-Oropeza et al. 2011). This is consistent with our model that predicts $80 \%$ of the fish species should be protected by marine reserves of that size.

An empirical telemetry study of movement patterns of two species (M. rosacea and L. argentiventris) in a marine reserve in the GOC also allowed us to further evaluate our model predictions (Online Resource 6). This study showed that $\sim 10 \%$ of individuals tagged from both species moved distances about twice as far we predicted with our model, suggesting we could be underestimating the minimum reserve size required for some individuals of these species. However, the long-distance movements of one of these species $(L$. argentiventris) were associated with spawning migrations rather than home range movements (which we used for our model). This highlights the need to integrate reserves with other management tools to protect species during long distance spawning migrations (as described in "Protecting critical, special unique sites" section).

Therefore, until more empirical movement data is available, we recommend that marine reserves should be $10 \mathrm{~km}$ or more across in the GOC because they are likely to protect most $(\sim 80 \%)$ species (Table 1 , Guideline 5). For larger species with widespread home ranges, it may not be possible to establish reserves that are large enough to protect them throughout their range (e.g. large sharks, billfishes or Humboldt squid Dosidicus gigas, which move 100 s or 1000 s of $\mathrm{km}$ : Fig. 4) (Gilly et al. 2012). Therefore, these wideranging species will need to be managed by protecting their critical areas at critical times (e.g. breeding or feeding areas) in combination with other non-spatial management tools (e.g. gear, seasonal or species bans: see "Protecting critical, special unique sites" section) (Table 1, Guideline 5).
Some focal species also use completely different habitats throughout their lives. For example, Sargassum spp. and mangroves forests act as nursery habitats for juvenile fishes in the GOC, while the adults primarily use rocky reefs (Aburto-Oropeza et al. 2007, 2009). Therefore, reserves should also be large enough to encompass all of their habitats and movements, or reserve networks should be designed to ensure that reserves are close enough to allow focal species to move among protected habitats within reserves (Table 1, Guideline 6). In areas where marine reserves are heavily fished at their boundaries, compact reserve shapes (e.g. squares or circles rather than elongated ones like rectangles) should also be used to minimize edge effects and maintain the integrity of the interior of the reserves (Green et al. 2009; McLeod et al. 2009), except when protecting naturally elongated habitats (e.g. long narrow reefs; Table 1, Guideline 7). Similar benefits can also be achieved by including complete ecological units (e.g. offshore reefs) in marine reserves (McLeod et al. 2009; Green et al. 2014) (Table 1, Guideline 8).

\section{Larval dispersal}

For populations inside a reserve to persist through time, larval supply must result in recruitment rates that equal or exceed mortality (ecological connectivity: Cowen and Sponaugle 2009). While lower levels of larval supply may play an important role in helping populations recover or adapt after disturbances (i.e., the minimum levels to maintain genetic connectivity), they are not sufficient to sustain populations over time (Cowen and Sponaugle 2009). Population persistence of focal species within marine reserves depends on recruitment to the local populations, either from larval production from within or outside reserves. Individual reserves can be self-persistent through larval retention where $>10-20 \%$ of larvae return to their natal source (Gaines et al. 2010), which is more likely where reserves are larger than the mean larval dispersal distance of focal species (Botsford et al. 2001; Green et al. 2015). Where fishing pressure is low or the fishery is well managed (at or below Maximum Sustainable Yield), larval input from fished areas can be important in ensuring population persistence of species within reserves and should also be considered in the design process (Botsford et al. 2014). However, in heavily fished areas like the GOC where larval input 


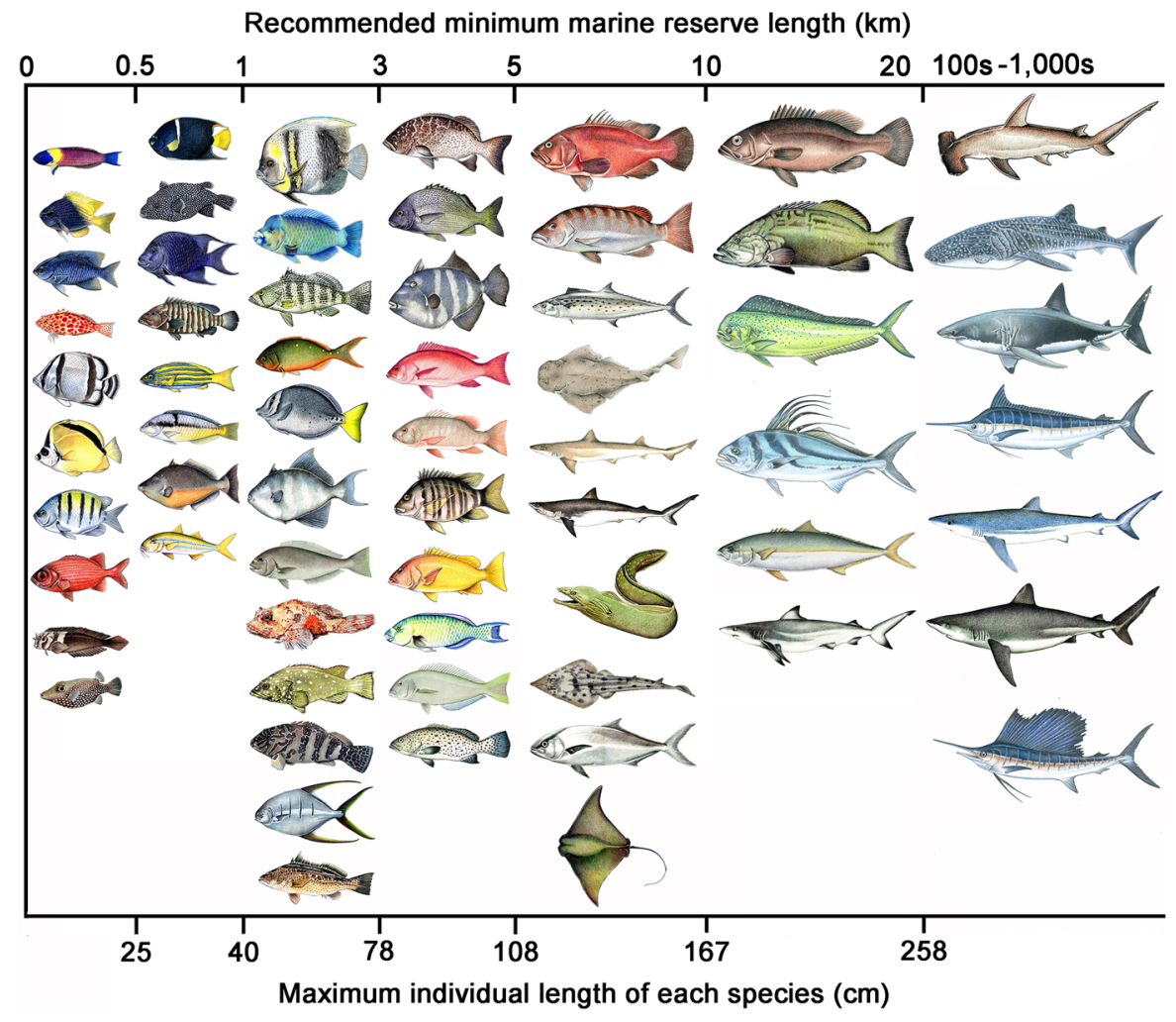

Fig. 4 Recommended minimum marine reserve length $(\mathrm{km})$ required for 63 fish species from the Gulf of California based on a regression model that employs the maximum individual length of each species as a predicting variable. Species were selected for demonstration purposes to represent a range of taxa, commercially important species and distinct trophic groups (see Online Resource 6 for details). We list species as shown from top to bottom assigned to each size interval with a $\pm 2 \mathrm{~cm}$ accuracy. 0-25 cm: Thalassoma lucasanum, Chromis limbaughi, Stegastes rectifraenum, Cirrhitichthys oxycephalus, Chaetodon humeralis, Johnrandallia nigrirostris, Abudefduf troschelii, Myripristis leiognathus, Ophioblennius steindachneri, Canthigaster punctatissima; 25-40 cm: Holacanthus passer, Arothron meleagris, Microspathodon dorsalis, Cephalopholis panamensis, Lutjanus viridis, Halichoeres nicholsi, Sufflamen verres, Mulloidichthys dentatus; $40-78 \mathrm{~cm}$ : Pomacanthus zonipectus, Scarus perrico, Paralabrax

from fished areas is likely to be low, populations of focal species may be sustained if reserves form mutually replenishing networks where each reserve contributes to the growth rate of the metapopulation, even if individual reserves are not self-persistent (Gaines et al. 2010). Green et al. (2014, 2015) recommended that to ensure the persistence of reserve populations, and to contribute to the replenishment of populations in heavily fished areas, marine reserves maculatofasciatus, Paranthias colonus, Prionurus punctatus, Balistes polylepis, Caulolatilus affinis, Scorpaena mystes, Epinephelus labriformis, Cirrhitus rivulatus, Trachinotus rhodopus, Paralabrax auroguttatus; 78-108 cm: Mycteroperca rosacea, Anisotremus interruptus, Pseudobalistes naufragium, Lutjanus peru, Lutjanus colorado, Hoplopagrus guentherii, Lutjanus argentiventris, Scarus ghobban, Caulolatilus princeps, Mycteroperca prionura; $108-167 \mathrm{~cm}$ : Hyporthodus acanthistius, Lutjanus novemfasciatus, Scomberomorus sierra, Squatina californica, Nasolamia velox, Rhizoprionodon longurio, Gymnothorax castaneus, Rhinobatos productus, Seriola rivoliana, Rhinoptera steindachneri; 167-258 cm: Hyporthodus niphobles, Mycteroperca jordani, Coryphaena hippurus, Nematistius pectoralis, Seriola lalandi, Carcharhinus limbatus; $>258 \mathrm{~cm}$ : Sphyrna lewini, Rhincodon typus, Carcharodon carcharias, Makaira nigricans, Prionace glauca, Carcharhinus obscurus, Istiophorus platypterus. Drawings by Juan Chuy

should be close enough to allow for strong larval connections among reserves and between reserves and fished areas (based on the mean larval dispersal distance of focal species).

How might these recommendations be adapted to the unique biophysical environment of GOC? This region is characterized by strong (e.g. $30-70 \mathrm{~cm} / \mathrm{s}$ ), consistent and unidirectional currents that are driven by oceanic gyres that change direction at the beginning 
of every spring (March) and fall (September) seasons (Lavin and Marinone 2003; Alvarez-Borrego 2010; Marinone 2012). There is little inter-annual variation in these seasonal patterns of oceanography, except during extreme ENSO events (Lavin and Marinone 2003; Alvarez-Borrego 2010; Paez-Osuna et al. 2016). In this aspect, the GOC differs from other regions where inter-annual oceanographic variability in connectivity is much larger than seasonal variation (California Bight: Watson et al. 2012).

Our understanding of larval dispersal in the GOC is based on a combination of three-dimensional oceanographic modeling for the Northern and Central GOC (Marinone et al. 2011; Marinone 2012), and model validation using population genetics and other empirical methods (Munguia-Vega et al. 2015b). These oceanographic models (Fig. 5, Online Resource 7) show currents in the Northern and Central GOC are predominantly asymmetric due to the semi-enclosed conditions caused by the presence of the Baja California Peninsula. A northward current is present along the eastern coast of the GOC between the springsummer (e.g. August, Fig. 5), transporting larvae to the north and causing a cyclonic (counter clock-wise) gyre in the Northern GOC; while a predominantly southward current is present along the eastern coast of the GOC moving larvae to the south during fall-winter (e.g. October, Fig. 5) and producing an anticyclonic (clockwise) circulation phase in the Northern GOC (Marinone 2012). These unique oceanographic conditions have strong implications for larval connectivity and marine reserve design.

Biophysical models and genetic studies indicate that larval dispersal kernels in the GOC are not spatially symmetrical but are highly constrained in particular routes by the direction of the currents driven by the narrow shape of the Gulf, particularly for species that spawn during a single season (Soria et al. 2012; Munguia-Vega et al. 2014, 2015a, 2018; TurkBoyer et al. 2014; Lodeiros et al. 2016; AlvarezRomero et al. 2018) (Fig. 5). Thus, larvae spawned in summer in the eastern coast of the GOC are more likely to move in a northerly direction, while those spawned in fall in the same location are more likely to move south (Fig. 5). In such a highly asymmetric current system, it is, therefore, very important that more marine reserves are located upstream of the direction of the flow during the spawning season of target species, since these areas act as larval sources to sustain metapopulations of those species (Green et al. 2014; Alvarez-Romero et al. 2018; Munguia-Vega et al. 2018) (Table 1, Guideline 9).

Many commercially important fisheries species studied to date spawn during spring and/or summer (Cudney-Bueno et al. 2009; Soria et al. 2014), so it will be important to protect upstream sources of larvae during this period (e.g. in permanent or seasonal marine reserves). However, focusing solely on spawning patterns of these species for reserve design will decrease protection of fall-winter spawners when the direction of the gyres and the location of upstream larval sources reverses. For example, at least some commercially important fishes (e.g. several tilefishes in the Genus Caulolatilus) and invertebrates (the geoduck clam Panopea globosa) also spawn exclusively during fall-winter (Ceballos-Vázquez and Elorduy-Garay 1998; Munguia-Vega et al. 2015a), so it will be important to protect upstream sources of larvae for these species. This is essential, because fishing tends to be concentrated at downstream sites for some fisheries species where larvae naturally accumulate, or in areas where there is high local retention of larvae (Cudney-Bueno et al. 2009; Munguia-Vega et al. 2014, 2015a; Alvarez-Romero et al. 2018).

Larval dispersal distances are also important to consider when spacing marine reserves in heavily fished areas (Green et al. 2014), such as the GOC. Studies elsewhere have noted that the magnitude of larval dispersal (i.e. the amount of larvae reaching a particular site) declines with increasing distance from the source population (Green et al. 2015). Thus as the distance between reserves increases, the amount of larvae they exchange (larval connectivity) decreases. However, given the strong, consistent asymmetric currents in the GOC, geographic distance alone is a poor predictor of ecological and genetic connectivity, because oceanographic distance follows the direction of the predominant current flow (Munguia-Vega et al. 2014, 2018; Soria et al. 2014; Lodeiros et al. 2016). Therefore, marine reserves in the GOC should be spaced using mean dispersal distances in the direction of the predominant flow (Table 1, Guideline 10). Another key factor to consider in understanding larval dispersal patterns is the Planktonic Larval Duration (PLD) of focal species. Our validated oceanographic models for the GOC predict that the average distance traveled by passive larvae is a function of their PLD 


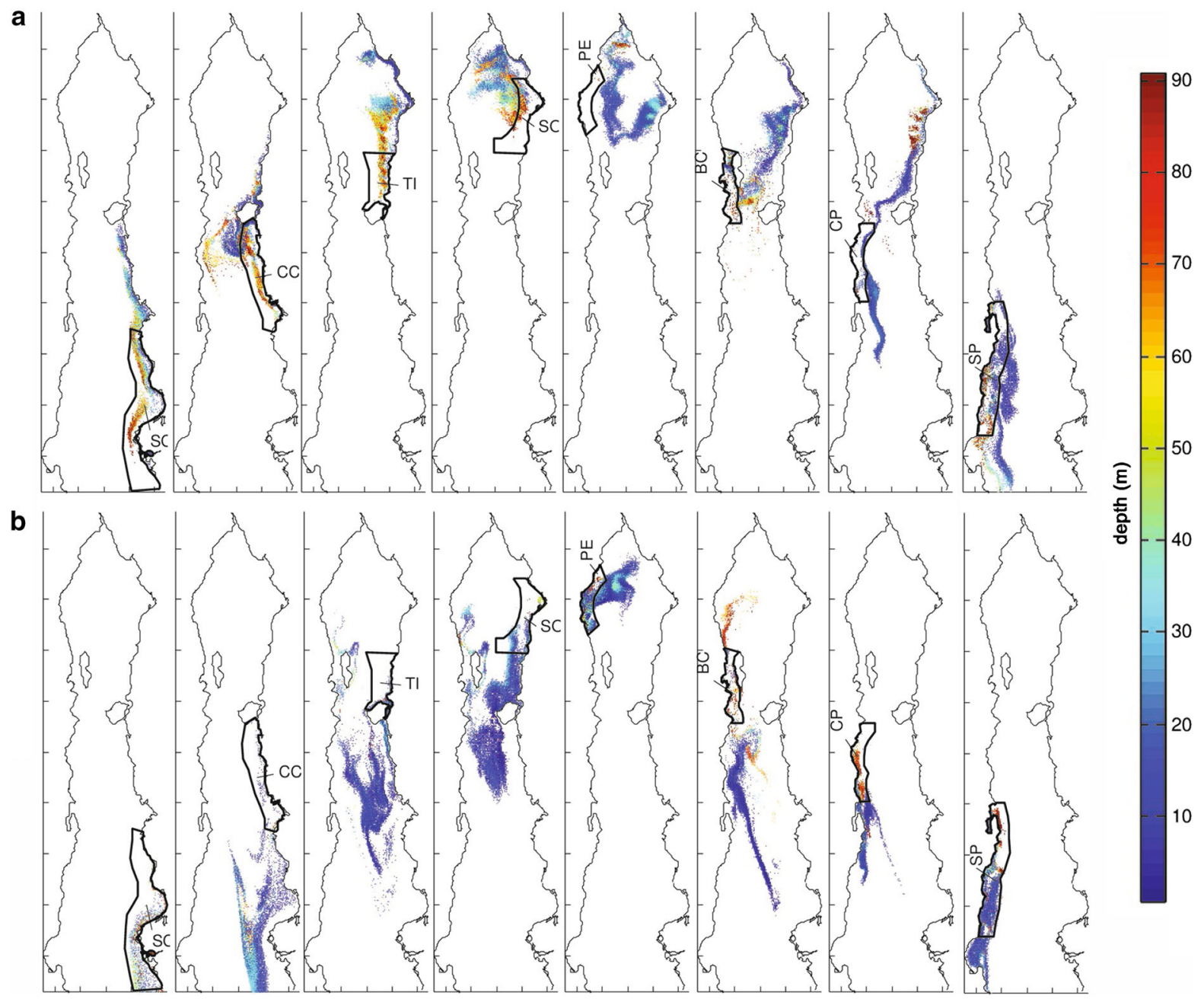

Fig. 5 Larval dispersal in the Gulf of California for species spawning during summer (a, August) and fall (b, October) with planktonic larval duration of 28 days, based on a three dimensional oceanographic model where larvae were released

varying from $>20$ to $80 \mathrm{~km}$ (PLD 7 days) up to $>$ 200 km (PLD 28-60 days, Online Resource 7) such that recommendations for reserve spacing might differ between taxonomic groups with different PLDs (Soria et al. 2014). Fish species associated with different habitats also seem to show statistically different dispersal profiles, with species from soft bottom habitats dispersing longer distances than those in other habitat types like rocky reefs (Anadon et al. 2013).

Larval dispersal distances also differ among different regions of the GOC. For example, larval dispersal distances are shorter on the deeper western side of the within each of eight coastal polygons shown in bold. Color shows the depth of virtual larvae. See Online Resource 7 for details

GOC due to vertical excursions of larvae to depths where currents flow in opposite directions to the surface currents, resulting in 5-10\% higher rates of larval retention compared to on the shallower, eastern side of the GOC (Marinone et al. 2011; Soria et al. 2012; Munguia-Vega et al. 2014). Furthermore, only a few sites in the GOC seem to show high levels of local larval retention related to oceanic eddies that form predominantly near the sharp ends of large islands (e.g. Angel de la Guarda, San Pedro Martir, Tiburon and Carmen islands, Fig. 1) (Munguia-Vega et al. 2014, 2018; Soria et al. 2014), and within bays with 
strong tidal currents (e.g. in the Upper GOC) (TurkBoyer et al. 2014).

Estimates of larval dispersal distances for the GOC indicate that increasing reserve size to guarantee high levels of larval retention within reserves may not be feasible, because most larvae move such long distances $(10 \mathrm{~s}$ or $100 \mathrm{~s} \mathrm{~km})$ that most sites are likely to depend on larval dispersal from upstream sources. Therefore, we recommend that in the GOC (depending on the PLD and spawning season of target species), marine reserves should be established either at sites where there are high levels of larval retention or where there are upstream sources of larvae, and they should be spaced 50-200 km apart to allow for high levels of larval connectivity among reserves (Table 1, Guideline 10).

\section{Allowing time for recovery}

Focal species differ in their vulnerability to fishing pressure and the rate at which their populations recover once fishing ceases. Recovery can be achieved in several ways depending on management objectives. For example, recovery of fish populations for biodiversity protection may be achieved when fish populations have reached their full carrying capacity (K) (Abesamis et al. 2014), or when populations have recovered to $90 \%$ of their unfished reef fish biomass (MacNeil et al. 2015). Alternatively, recovery of fish populations for fisheries management could mean that they have reached a level where they can sustain fishing pressure (e.g. where $\sim 35 \%$ of unfished stock of reproductive biomass is protected to ensure adequate replacement of stocks for a range of species) (Botsford et al. 2001; Fogarty and Botsford 2007). Another approach is to assess recovery in terms of when fish populations have recuperated enough to maintain their functional role in the ecosystem (MacNeil et al. 2015).

Many life history characteristics influence the recovery times of populations of fisheries species, including maximum body size, individual growth rate, longevity, age or length at maturity, rate of natural mortality and trophic level (Abesamis et al. 2014). For example, populations of larger-bodied carnivorous fishes (e.g. groupers, snappers, emperors and jacks) are more susceptible to overfishing (Sala et al. 2004) and tend to take longer to recover than smaller-bodied species lower in the food web (e.g. planktivores and herbivores) (Abesamis et al. 2014). The rate of population recovery also depends on other factors including species composition, demographic and habitat characteristics, interspecific interactions and reserve size (Abesamis et al. 2014). Several empirical studies have demonstrated that because recovery rates differ among species, it may be necessary to protect populations over long periods of time ( $>20$ years), preferably permanently, to allow populations of all trophic groups to recover, particularly large carnivores (Abesamis et al. 2014; Green et al. 2014). Similarly, monitoring in temperate kelp forests in California demonstrated that while fishery target species have increased significantly $(\sim 200 \%)$ in biomass after 10 years of protection, they have not reached their K (Caselle et al. 2015).

How long do marine reserves need to be in place in the GOC to allow for the recovery of populations of focal species? The best empirical monitoring data in the region is from Cabo Pulmo National Park, where the first biological assessment of the recovery of marine resources was conducted after 4 years of protection. This assessment did not provide evidence of reef fish biomass recovery or significant differences in the mean biomass in the park compared to open access areas or other (poorly enforced) protected areas in the region (Aburto-Oropeza et al. 2011). A second assessment was performed after 14 years of protection, and results showed that the total fish biomass had increased by $\sim 463 \%$, especially for top predators and other carnivores (which showed 11-fold and fourfold increases in biomass respectively). Individual fish sizes and the relative proportion of top predators in the fish community had increased also, but populations in the reserve were still undergoing recovery (AburtoOropeza et al. 2011).

By using a catch-only method to estimate fisheries reference points, we incorporated 15 years of fisheries landings data from the areas of $\mathrm{La} \mathrm{Paz}$ and Loreto in the Central GOC (Fig. 1) and we estimated the maximum intrinsic rate of population growth $(r)$ and the carrying capacity $(\mathrm{K})$ for four groups of species, including herbivores (parrotfishes), planktivores (pacific creole fish), carnivores (grunts, wrasses, etc.) and piscivores (groupers, snappers, jacks, etc.) (Online Resource 8) (Froese et al. 2017). Figure 6 shows the recovery trajectories of these groups of species assuming they are fully protected in reserves after being diminished to $20 \%$ of their $\mathrm{K}$ by fishing. The 
results show that while herbivores and planktivores can recover to $95 \%$ of the full $\mathrm{K}$ in 8 and 11 years respectively, carnivores and piscivores would take 22 and 24 years, respectively, to do so. This pattern is explained by the differences in carrying capacity, which allows lower trophic levels to recover faster due to their high $\mathrm{r}$ and lower $\mathrm{K}$ values (Online Resource 8). Therefore, since reef fish populations are likely to take decades to recover in the GOC, we recommend that marine reserves should be established for the long term ( $>25$ years), preferably permanently (Table 1 , Guideline 11). Permanent protection and strict enforcement of marine reserves will also avoid considerable delays in recovery time and ensure that these benefits are maintained in the long term (Abesamis et al. 2014; Green et al. 2014).

Shorter term marine reserves are only likely to provide limited benefits for some species, and these benefits will be quickly lost once these areas are reopened to fishing unless they are managed very carefully (Abesamis et al. 2014) which is seldom the case. Therefore, if shorter-term reserves are established in the GOC, they should be used in addition to, rather than instead of, permanent marine reserves (Table 1, Guideline 12). The exception is seasonal closures to protect critical areas at critical times (e.g. FSAs or nursery areas), which can be very important to protect or restore populations of focal fisheries species (see "Protecting critical, special unique sites" section).
Considering threats and opportunities

Local anthropogenic threats can seriously degrade marine ecosystems, decreasing ecosystem health, productivity, and ecosystem resilience to climate change and other stressors, adversely affecting focal species and undermining the long-term sustainability of marine resources and the ecosystem services they provide (Green et al. 2014). Some of these threats may originate from marine activities such as overfishing and shipping impacts (Halpern et al. 2008). Others originate from the terrestrial environment, including runoff from poor land use practices associated with deforestation, agriculture, mining, urban and coastal development (Roberts et al. 2002) and need to be addressed by integrating reserves within broader coastal management regimes (Green et al. 2014).

Over the last 10 years, there have been global assessments (WCS and CIESIN 2005; Halpern et al. 2008, 2015) and many regional assessments that provide overviews of local threats to marine ecosystems and how they vary in the GOC. Not surprisingly, all of these studies have found that higher impacts are associated with areas that have larger human populations and higher fishing intensities (Fig. 7). Halpern et al. (2008) assessed cumulative human impacts to marine ecosystems worldwide from 17 anthropogenic drivers, including industrial and artisanal fishing, ocean-based pollution, ocean acidification, shipping, sea surface temperature, UV radiation, invasive species and light, nutrient and inorganic pollution
Fig. 6 Recovery trajectories of four trophic groups of reef fishes to $95 \%$ (dotted line) of their full carrying capacity $(\mathrm{K})$ in the Central Gulf of California, developed using a Schafer production model that assumed that all four groups were depleted to $20 \%$ of their $\mathrm{K}$ before being protected within marine reserves. See Online Resource 8 for details

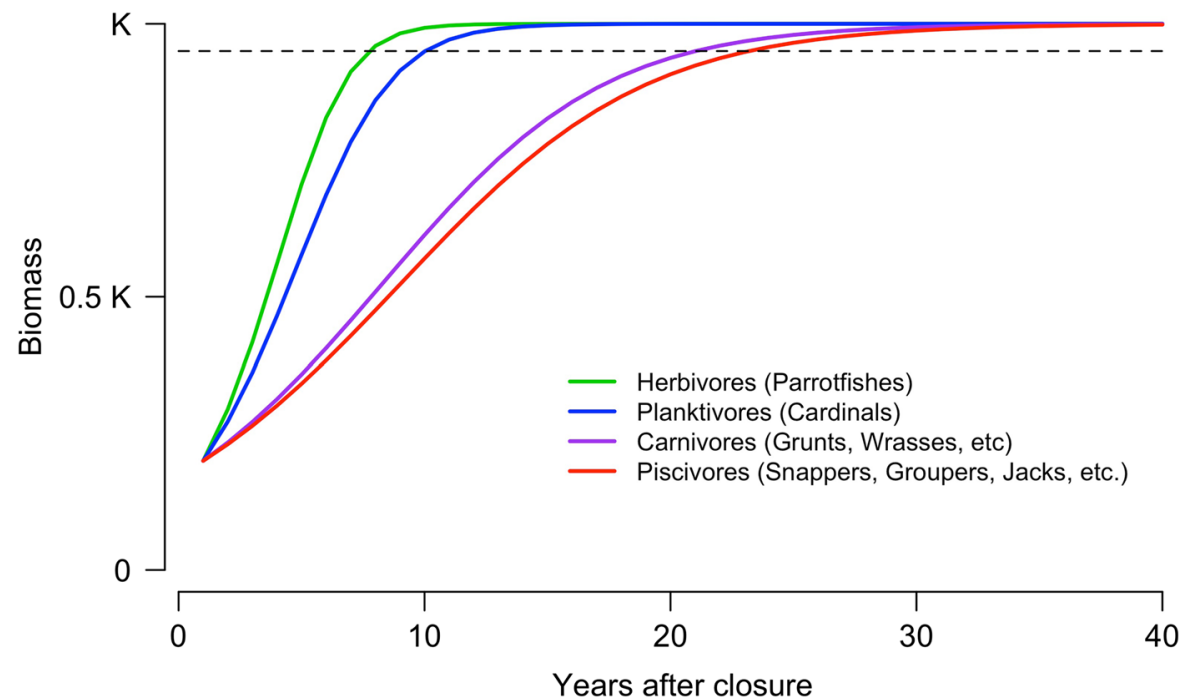



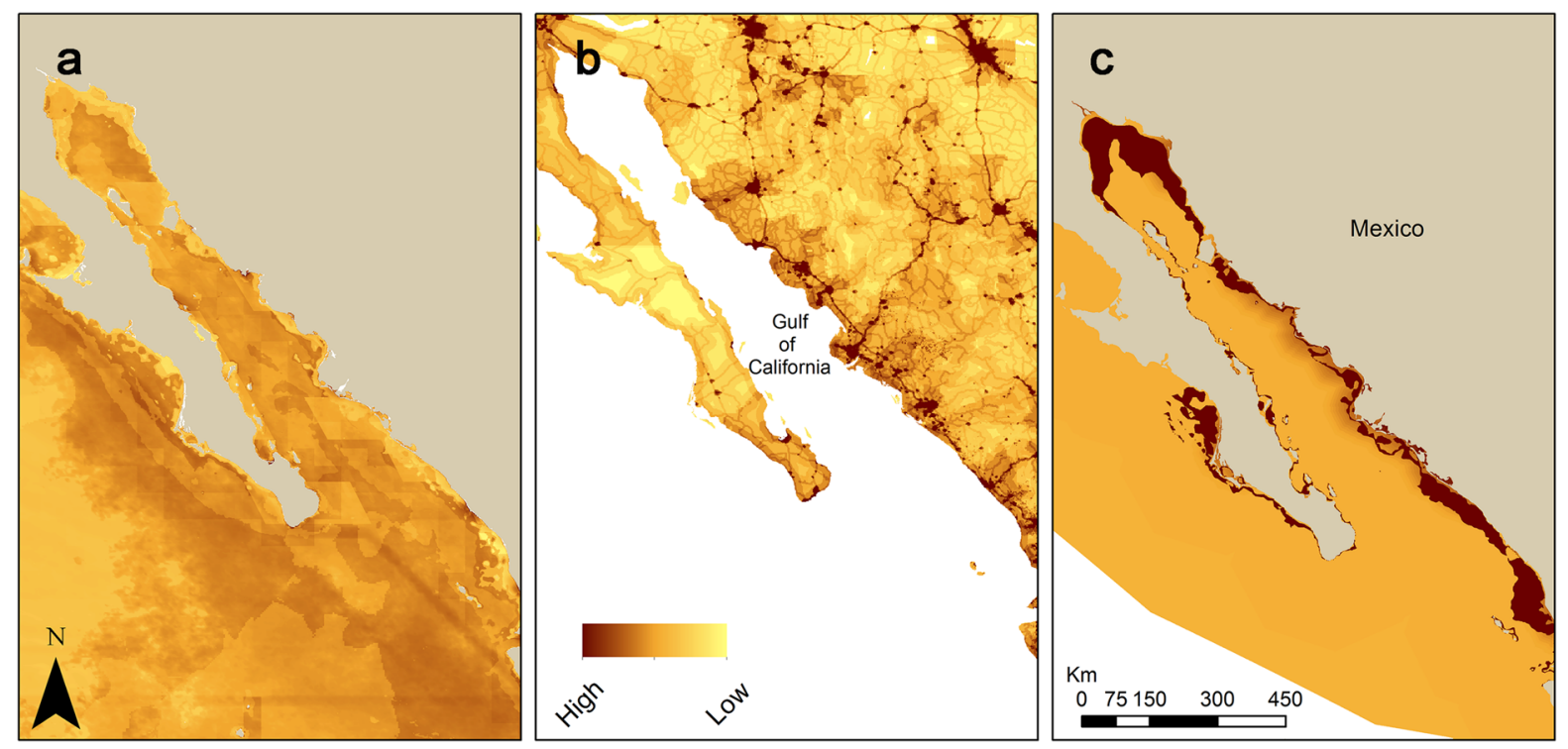

Fig. 7 Distribution of local anthropogenic threats in the Gulf of California. a Cumulative human impacts to marine ecosystems in the GOC (excerpt from a global analysis by Halpern et al. 2008), b land-based human threats to coastal environments

(Fig. 7a). Their results show that cumulative human impacts to marine ecosystems seem to be lower around the Midriff Islands compared to most other areas in the Upper, Central and Southern GOC (Fig. 7a).

The Global Human Footprint dataset (WCS and CIESIN 2005) also identified the level of anthropogenic land based impacts on the coastal environment, shown as a composite index normalized by biome and based on global human population pressure (population density), human land use and infrastructure (built-up areas, nighttime lights, land use/land cover), and human access (coastlines, roads, railroads and navigable rivers: Fig. 7b). They found that the west coast of the GOC appears to have low levels of land based threats because it is inaccessible and has a low human population density, except for the northern and southern tips of the peninsula where there are rapidly growing developments (Fig. 7b), a trend that continues based on a recent study (Gonzalez-Abraham et al. 2015). In contrast, land based threats are much higher along the east coast of the GOC, in part driven by land-based nutrient pollution from farming activities that represent a potential risk to marine areas (Alvarez-Romero et al. 2015). Many coastal lagoons along the eastern margin of the GOC also exhibit signs of increased sedimentation and growing volumes of (excerpt from a global analysis by WCS and CIESIN 2005); and c threats from fishing based on socioeconomic information (Haro-Martinez et al. 2000)

agricultural runoff and eutrophication from shrimp farming (Paez-Osuna et al. 2016), while coastal wetlands have been steadily receding due to conversion to tourism developments and aquaculture (Carvajal et al. 2010).

There have also been several regional assessments that provide overviews of local threats to marine ecosystems and how they vary throughout the GOC (Cubero-Pardo et al. 2011; Alvarez-Romero et al. 2013; Morzaria-Luna et al. 2014). For example, HaroMartinez et al. (2000) used a multicriteria, processdriven approach to calculate the potential spatial dispersion of environmental pressure (or threats) derived by human activities. They modeled this using a Pressure-State-Response approach and GIS, which provided an understanding of the geographic distribution of pressures. For example, the Upper GOC and the eastern margin of the GOC (in Sinaloa and Sonora states) show high levels of threats where most fishing activities take place, while pressures are lower along the western side of the GOC (Fig. 7c). A recent publication provided a similar spatial distribution of fishing pressure calculated as a function of the spatial pattern of human population density and boat density (Johnson et al. 2017). 
To maximise the benefits for biodiversity conservation and fisheries management in the GOC, we recommend protecting areas in marine reserves where habitats and populations are likely to be in the best condition both now and in the future (reviewed in Green et al. 2014) by: avoiding establishing reserves in areas with local anthropogenic threats that cannot be controlled within the reserve (e.g. high human population density, land-based run-off, shipping and coastal development); establishing reserves in areas that have lower levels of threats; and considering the cumulative effects of multiple threats in each location (Table 1, Guidelines 13-15, Fig. 7). We also recommend protecting areas that are less likely to be exposed to local threats in the future by placing marine reserves within or adjacent to other effectively managed coastal and terrestrial areas.

\section{Climate change adaptation}

Climate change is causing significant physical changes in the world's oceans, including increased sea-surface temperatures, changes in coastal upwelling, shifts in tropical storm activity, ocean acidification and reduced oxygen solubility, which in conjunction with changes in ocean stratification and changes in circulation, can lead to low oxygen levels (reviewed in Roberts et al. 2017). Physical changes to ocean systems will likely intensify in coming decades (Roberts et al. 2017), altering species distributions, growth, abundance and population connectivity (Gerber et al. 2014), while causing fundamental modifications to marine ecosystems through complex effects on both bottom-up and top-down processes (Soto 2002).

Networks of marine reserves can promote ecosystem resilience to climate-related stresses by protecting key habitats and species from other anthropogenic stressors (e.g. overfishing), maintaining connectivity patterns and genetic variability, protecting nursery and spawning areas, and spreading the risk from negative disturbance events (McLeod et al. 2009; Gerber et al. 2014; Roberts et al. 2017). Marine reserves are rarely designed to consider the effects of climate change (Soto 2002; Beger et al. 2015), and are therefore not able to optimize potential benefits for climate change adaptation (Hopkins et al. 2016).

Therefore, when designing new networks of marine reserves, it is important to take climate change into account. For example, it is important to identify and protect refugia within marine reserves where habitats and species are likely to be more resistant or resilient to climate change including: areas where habitats and species are known to have withstood environmental changes (or extremes) in the past; areas with historically variable sea-surface temperature (SST) and ocean carbonate chemistry, where habitats and species are more likely to withstand changes in those parameters in the future; and areas adjacent to low-lying inland areas without infrastructure where coastal habitats (e.g. mangroves, tidal marshes) can expand into as sea levels rise (Green et al. 2014). It may also be important to protect areas in marine reserves that could serve as mitigation (i.e. wetlands or other areas important for carbon storage) (Hopkins et al. 2016).

How are changes in climate and ocean chemistry likely to affect marine ecosystems in the GOC, and how should we take this into account when designing a network of marine reserves? Globally, the ocean surface warmed $0.11{ }^{\circ} \mathrm{C}$ between 1971 and 2010 (IPCC 2013), and global circulation models project an increase of $2-3{ }^{\circ} \mathrm{C}$ in the top $100 \mathrm{~m}$ under the Representative Concentration Pathway (RCP) 8.5 scenario by year 2050 (IPCC 2013). The RCP 8.5 scenario represents ongoing emissions and delayed responses in global temperature, which will lead to increasing temperatures. In the GOC, temperature trends vary from increasing between 1950-1999 and 1999-2006, to moderately decreasing between 1985 and 2011 (Lluch-Cota et al. 2013). These patterns may be driven by the interaction of anthropogenic climate change effects and large scale patterns of climatic variability including the Pacific Decadal Oscillation (PDO) and ENSO events (Lluch-Cota et al. 2013). Meanwhile, ocean acidification in the GOC is predicted to increase, stemming from a decrease of -0.25 to $-0.4 \mathrm{pH}$ units. Sea level trends in the GOC from 1993 to present averaged an increase of $2.5 \pm 1.1 \mathrm{~mm} /$ year, which is compatible with global trends (Paez-Osuna et al. 2016). However sea level increases in the deeper central GOC were less $(0.1 \pm 0.3 \mathrm{~mm} /$ year $)$ than in the Southern GOC $(0.8 \pm 0.8 \mathrm{~mm} /$ year $)$ and the shallow Upper GOC $(2.0 \pm 0.4 \mathrm{~mm} /$ year) (Paez-Osuna et al. 2016). Fisheries production in the GOC is also predicted to decrease under climate change, in a similar way to the documented effects of ENSO due to deepening of the thermocline and nutricline, suppression of upwelling 
and reduction of primary productivity mainly in the Southern GOC (Paez-Osuna et al. 2016).

Climate change may also affect larval connectivity among marine reserves by shortening PLDs, reducing reproductive output, changing the speed and direction of ocean currents and causing habitat loss (Gerber et al. 2014), and marine reserve number, location and spacing may need to be adapted accordingly. For example, the current PLD of $M$. rosacea, the most heavily fished grouper in the GOC, may be reduced from 28 to 21 days with an average increase in temperature of $3^{\circ} \mathrm{C}$, significantly decreasing the connectedness of marine reserve networks for rocky reefs in the asymmetric currents of the GOC, while shifting the importance of present day upstream larval sources to sites located more downstream in the direction of the flow (Alvarez-Romero et al. 2018). This means that reserves may need to be larger and closer and/or networks may need to include more reserves to maintain larval connectivity in the future (Alvarez-Romero et al. 2018).

Climate change effects on habitat distribution are also predicted to affect biological interactions among species (e.g. predator-prey, mutualism, competition, habitat use, etc.) (Doney et al. 2012). For example, recruitment success of commercial fishes like $M$. rosacea that depends upon the availability of Sargassum spp. forests as nursery habitat (Aburto-Oropeza et al. 2007) could increase in some areas of the GOC and decrease in others. Using niche modeling (Elith et al. 2011) based on 11 and 13 selected environmental variables we modeled the preferred habitat for $M$. rosacea and Sargassum spp, respectively, for current (2015) and future (2050) SST conditions according to the RCP 8.5 future emission scenario (Online Resource 9). We then identified the areas in the GOC where the range of each species is likely to expand, contract or remain stable, including those areas where the ranges of the two taxa overlap spatially. Our models predict a range contraction for M. rosacea in the Central GOC that is consistent with a previous study that predicted a decline in the abundance of this species (Ayala-Bocos et al. 2016) with a small expansion into new habitats on the southwestern portion of the Northern GOC (e.g. Bahía de los Angeles) and into the Southwestern Pacific coast of the Baja California peninsula outside of the GOC (e.g. Bahía Magdalena) (Fig. 8a). Our models also predict range contractions for Sargassum spp. in the central GOC and gains around the Midriff Island Region in the northern GOC (Fig. 8b). The overlap between the ranges of the two species seems mainly limited by the distribution of the nursery habitat, which is much more constrained than that of the grouper. Our analysis predicts that the spatial interaction between the two species will remain stable (i.e. in refuges) at only a few areas such as between Angel de la Guarda and Tiburón Island in the Northern GOC (Fig. 8c), which is an
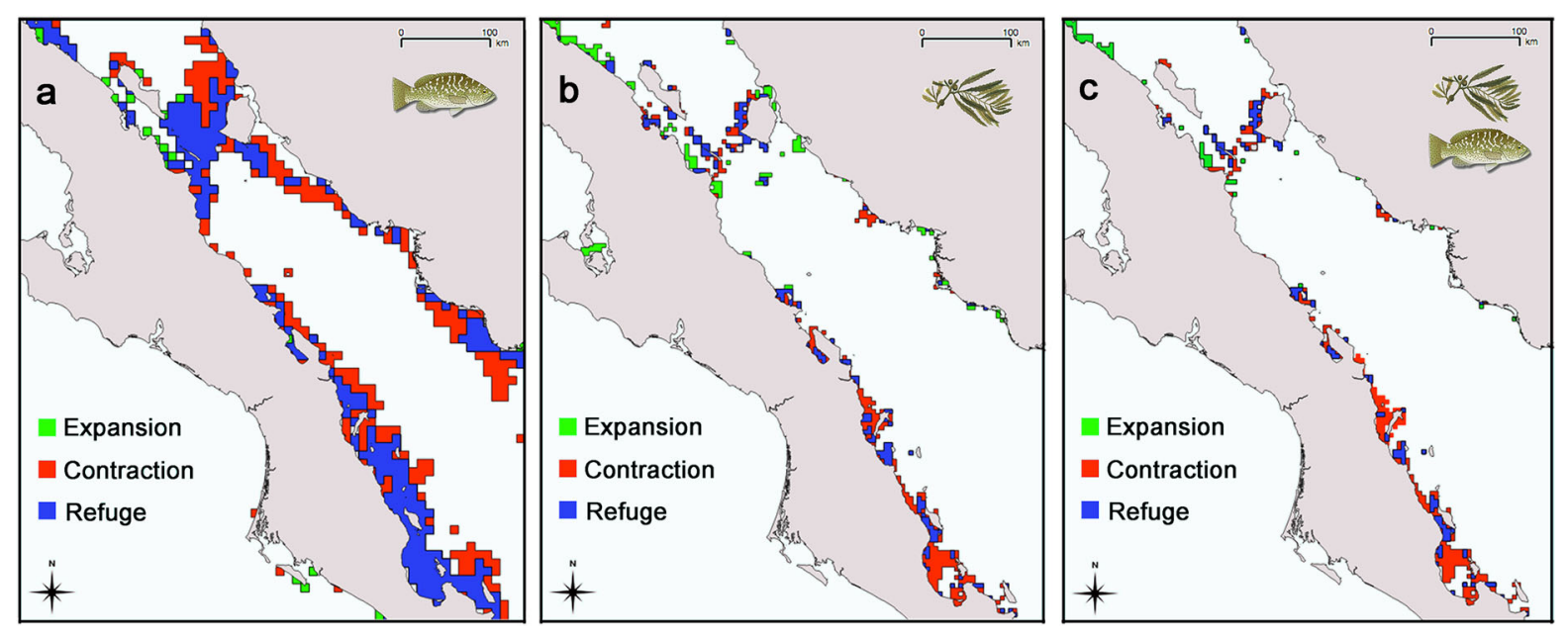

Fig. 8 Projected changes in distribution from 2015 to 2050 based on estimated increases in sea surface temperature under RCP 8.5 for: a leopard grouper Mycteroperca rosacea, $\mathbf{b}$ its nursery habitat Sargassum spp. forests, and $\mathbf{c}$ areas where the ranges of both species overlap. Green areas represent range expansions, red areas indicate range contractions, and blue areas indicate range stability (refuges). See Online Resource 9 for details 


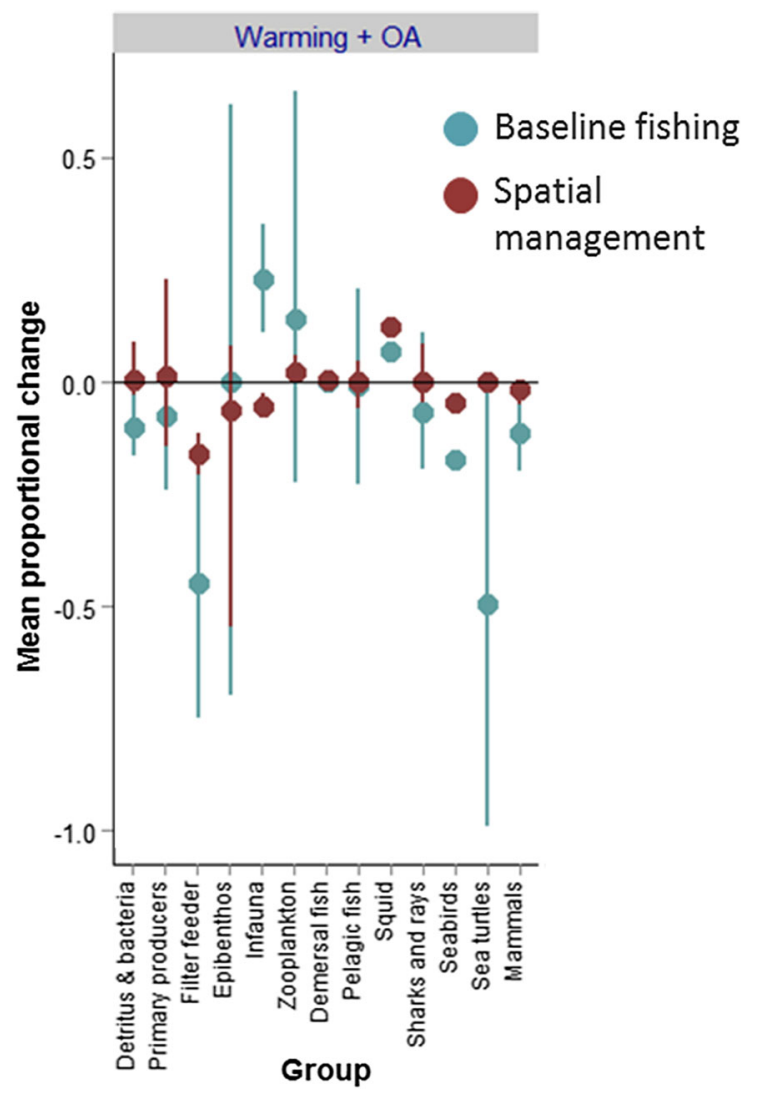

Fig. 9 Proportional change in biomass of 13 trophic or taxonomic groups under a scenario of ocean warming and ocean acidification (OA) based on an Atlantis ecosystem model for the Northern Gulf of California. Dots represent average projected positive (above zero) or negative (below zero) changes in mean biomass ( $\pm 95 \%$ confidence interval), considering baseline fishing levels (Baseline fishing) or if current spatial fisheries management restrictions are in place (Spatial management) assuming compliance with existing marine reserves and other fishing regulations within Marine Protected Areas. Morzaria-Luna (2016): see Online Resource 10 for details

important area for larval sources that sustain fisheries for this species (Munguia-Vega et al. 2014; AlvarezRomero et al. 2018). The models also identified new areas in the southwestern section of the Northern GOC where the range of these two taxa will overlap more in the future (Fig. 8c). Areas likely to support or maintain important biological interactions between species now and into the future should be prioritized for protection within marine reserves.

Ecosystem modeling of climate change effects indicates that marine reserves may differentially buffer climate change effects on marine ecosystems in the GOC. Morzaria-Luna (2016) tested scenarios simulating the effects of future ocean warming (projected under RCP scenario 8.5) and ocean acidification (representing general effects of lower $\mathrm{pH}$ on marine organisms) on 13 trophic or taxonomic groups (See Online Resource 10 for details) employing the Atlantis ecosystem model for the Northern GOC (Ainsworth et al. 2011). Atlantis generates multispecies projections of stock trends through time and provides indicators of ecosystem structure and function. A first scenario based on a combination of the effects of ocean warming and ocean acidification considering baseline levels of fishing indicated that about half of the functional groups will show declines in biomass that are moderate (detritus and bacteria, primary producers, sharks and rays, seabirds and marine mammals) or strong (filter feeders, sea turtles, Fig. 9). These reductions in biomass could be interpreted as direct effects on mortality and growth or indirect effects through restructuring of the food web. Other animal groups are projected to show little or no effects in the GOC (epibenthos, demersal and pelagic fishes), while a few groups could benefit from climate change (infauna, zooplancton and squid). A second scenario replicated the first but assumed compliance to existing marine reserves and other spatial fishing regulations within MPAs. Results of the second scenario suggested that for most groups affected negatively by climate change, spatial fisheries management including marine reserves could potentially ameliorate the effects on their biomass (Fig. 9). A recent paper assessing the effect of MPAs across multiple Atlantis ecosystem models, including the Northern GOC model, also found that MPAs led to both 'winners' and 'losers' at the level of particular species or functional groups (Olsen et al. 2018).

To adapt to changes in climate and ocean chemistry, we recommend: prioritizing areas for protection where habitats and species are likely to be more resistant or resilient to climate change; considering climate change effects on larval dispersal, distribution, growth, reproduction, and recovery rates of species and implications for the location, spacing and duration of marine reserves; and considering the effects of climate change on ecosystem function and dynamics (e.g. changes in relative biomass of trophic groups, and changes due to variations in nutrient recycling/ upwelling) and implications for design guidelines regarding habitat representation and replication, 
protecting critical, special and unique areas, and allowing time for recovery (Table 1, Guidelines 16-19).

\section{Discussion}

A case study for refining ecological guidelines for marine reserve design in the Gulf of California

Here we provide a case study of how to adapt and refine broad ecological guidelines for designing networks of marine reserves in a specific location. Using the best scientific information, we provide 19 ecological guidelines for designing networks of marine reserves for the GOC (Table 1) that consider the unique biophysical, ecological and evolutionary history of this ecosystem. These guidelines are based on our review of the published literature and new analyses, which can be refined when more information on key research gaps (see below) becomes available. Our rationale for adapting ecological guidelines to the local context relies on the logic that networks of marine reserves in the GOC designed using the guidelines presented here will have a better chance of meeting ecological goals related to improving fisheries management, biodiversity conservation and climate change adaptation, than if they were designed using general guidelines developed elsewhere.

The ecological guidelines that we provide have many similarities with those provided by previous studies, but we refined these to provide specific advice for the GOC. For example, many studies agree regarding the importance of habitat representation and replication, and the protection of critical areas in the life cycle of focal species and unique sites of outstanding biological value (e.g. Jessen et al. 2011; Green et al. 2014; this study). However, these studies differ in terms of the specific details (i.e. which habitats, species and critical areas need to be protected in different ecosystems and geographic locations).

We also used several approaches to provide a scientific basis for developing design criteria in a specific location. For example, we used the best available existing information (e.g. to define habitat types for representation and replication), and synthesized existing information from local modeling studies validated with empirical data (e.g. to develop a model to describe larval dispersal and implications for the location and spacing of reserves). We also used innovative approaches to develop the design guidelines by: using data from local scientific studies in combination with global initiatives (e.g. to develop a model to predict species richness patterns and a niche model of the interaction of species under climate change); and developing new models based on limited available information, either by employing local data (e.g. to develop a model to estimate recovery times to inform reserve duration) or using empirical data from other geographic areas to inform local models (e.g. to develop a model of recommended marine reserve sizes).

The results of our new analyses for adapting ecological guidelines to the GOC were sometimes remarkably similar to those of previous studies for tropical marine ecosystems and species. For example, our recovery times for herbivorous and carnivorous fishes ( $\sim 10$ and $20+$ years, respectively) and recommended reserve durations were similar to those recommended elsewhere (e.g. Abesamis et al. 2014). Our recommended marine reserve size to protect most fishes $(\geq 10 \mathrm{~km})$ is also consistent with previous studies (Green et al. 2015; Krueck et al. 2018).

However, in other instances we developed new versions of the design criteria that have not been used previously, including recommendations regarding marine reserve location and spacing to maintain larval connectivity when oceanic currents are strongly asymmetric. These results emphasize the need to refine design guidelines for different geographies, because applying general guidelines developed elsewhere may have reduced the effectiveness of networks of marine reserves if we had applied them in the GOC.

Failure to apply these guidelines may result in inadequate levels of protection to maintain ecosystem health, function and populations of focal species, which may lead to biodiversity loss, population declines, delays in the recovery of focal species, and increased vulnerability of habitats and species to climate change. Furthermore, these guidelines need to be applied simultaneously, since reserves with only a few desirable criteria may not be ecologically distinguishable from fished sites (Edgar et al. 2014). 
Integrating ecological, socioeconomic

and governance design guidelines

In addition to developing ecological guidelines for designing a network of marine reserves in the GOC, it was extremely important to develop socioeconomic and governance (SEG) guidelines to consider human uses and values, and to align the network with local legal, political and institutional requirements (e.g. see Fernandes et al. 2005; Green et al. 2009; Jessen et al. 2011). A bottom-up strategy focused on social justice, inclusion and human dimensions needs to be in place and weighted equally with ecological guidelines so the reserves are legitimized and supported by users, both for ethical and practical reasons (Bennett 2018).

Recently, SEG guidelines were developed for designing a network of marine reserves for the GOC (Bennett et al. 2017) using a similar process of participatory workshops that we used to develop the ecological guidelines described in this study. These SEG guidelines have the following key objectives: (1) integrate the social context, aspirations and interactions with the natural environment to support human wellbeing, (2) respect and maintain cultural diversity, identity and activities, (3) consider economic and noneconomic uses and values to promote equitable distribution of impacts and benefits, (4) ensure management effectiveness, (5) implement adaptive management, and (6) establish and ensure legitimacy and institutional continuity (Bennett et al. 2017).

Both the ecological and SEG guidelines will be used in a comprehensive planning process for designing and implementing a network of marine reserves in the GOC. This will provide a sound framework for discussing potential tradeoffs and complementarity between both sets of guidelines. For example, fishing zones, which are mainly located downstream relative to the oceanic currents that transport larvae, have a higher economic value than upstream fishing zones (Alvarez-Romero et al. 2018). Thus, prioritizing upstream sources of larvae for protection within marine reserves could result in a more connected and resilient network at comparatively lower socio-economic costs (Alvarez-Romero et al. 2018).

Future research priorities

While developing these ecological guidelines (Table 1), we identified the following research priorities for adapting, refining and applying the guidelines for marine reserve design in the GOC in the future. At present there is a lack of information on the distribution of some of the most important habitats. For example, sandy bottoms occur throughout the entire GOC and are estimated to harbor $\sim 40 \%$ of all invertebrate species (Brusca and Hendrickx 2010), yet there is little information available to delineate their boundaries. Similarly, rocky reefs and rhodolith beds in the Southern GOC have not been thoroughly mapped. The spatio-temporal variation in Sargassum spp. forests is also understudied.

Some special and unique areas are also poorly mapped, including black coral habitats, FSAs for multiple species, and hotspots of endemic species for several taxonomic groups. More studies of many invertebrate and planktonic communities are also required, since it is estimated that half of the animal diversity of the GOC still needs to be described (Brusca et al. 2005). Conservation of biodiversity and uniqueness below the species level (populations, genes) within reserves is also needed to maintain evolutionary potential (Jessen et al. 2011), but our understanding of genetic diversity in the GOC is fragmented and limited to particular species and localities (e.g. Munguia-Vega et al. 2015b). However, cryptic phylogenetic diversity seems to be high (e.g. Riginos 2005). Further research is also needed into the extent of trade-offs that might be required in the GOC when trying to achieve multiple goals, for example between protecting upstream larval sources for enhancing fisheries (Munguia-Vega et al. 2014, 2018) or downstream sites that may contain higher genetic diversity and adaptation potential (Munguia-Vega et al. 2015a; Lodeiros et al. 2016).

More information is also required to validate and refine our model predictions for movement patterns of juveniles and adults of focal fish species in the GOC, particularly empirical measurements of home ranges, spawning migrations and ontogenetic habitat shifts of focal species. These studies should also be conducted not only for fishes but for commercially important invertebrates that have mobile adult phases (e.g. swimming crab, lobster, octopus). Further studies are also required to document spawning times, PLD, larval dispersal, and metapopulation dynamics for focal species (particularly for species that spawn during the fall-winter), including studies of larval dispersal in the Southern GOC. More long term 
monitoring of marine reserves and adjacent areas is also required to estimate regional and species-specific recovery rates of focal species. It is also important to collect empirical data to validate if multiple marine reserves are functioning as ecologically connected networks (Gaines et al. 2010).

Perhaps the most important research priority is the need to understand more about the potential effects of climate change on the distribution and abundance of major habitats and focal species, life history traits within species (e.g. spawning times, PLDs, growth rates and survival), and associated changes in communities, trophic and connectivity networks in the GOC. Further monitoring and modeling of changes in the distribution of species under climate change could also be used to inform where interactions between species (and people) will be lost, gained, or remain stable in the future to determine potential winners and losers (Cavole et al. 2016). It will also be critical to model the cumulative impacts of climate change and other threats (e.g. overfishing), and the likely regional frequency of extreme events (e.g. hurricanes or ocean heat waves). Understanding more about these local and global threats and their potential impacts on major habitats and species will be critically important for designing resilient networks of marine reserves that will maximize the benefits for both people and nature in the long term in the GOC.

Acknowledgements We thank the scientists and managers (Online Resource 2) who contributed their expertise to develop these ecological guidelines. This work was primarily funded by The Nature Conservancy and Fundación Televisa. Complementary support was provided by The David and Lucile Packard Foundation, Walton Family Foundation, Sandler Supporting Family Foundation, Marisla Foundation, World Wildlife Fund-Carlos Slim Foundation Alliance, the University of Arizona-CONACYT CAZMEX consortium, BIOMAR-GIZ, CONACYT, Microsoft Azure Research and CONANP. Authorship after the fourth author follows an alphabetical order.

\section{Compliance with ethical standards}

Conflict of interest The authors declare that they have no conflict of interest.

Open Access This article is distributed under the terms of the Creative Commons Attribution 4.0 International License (http:// creativecommons.org/licenses/by/4.0/), which permits unrestricted use, distribution, and reproduction in any medium, provided you give appropriate credit to the original author(s) and the source, provide a link to the Creative Commons license, and indicate if changes were made.

\section{References}

Abesamis RA, Green AL, Russ GR, Jadloc CRL (2014) The intrinsic vulnerability to fishing of coral reef fishes and their differential recovery in fishery closures. Rev Fish Biol Fish 24:1033-1063. https://doi.org/10.1007/s11160-0149362-x

Aburto-Oropeza O, Sala E, Paredes G, Mendoza A, Ballesteros E (2007) Predictability of reef fish recruitment in a highly variable nursery habitat. Ecology 88:2220-2228

Aburto-Oropeza O, Ezcurra E, Danemann G, Valdez V, Murray J, Sala E (2008) Mangroves in the Gulf of California increase fishery yields. Proc Natl Acad Sci USA 105:10456-10459. https://doi.org/10.1073/pnas. 0804601105

Aburto-Oropeza O, Dominguez-Guerrero I, Cota-Nieto J, Plomozo-Lugo T (2009) Recruitment and ontogenetic habitat shifts of the yellow snapper (Lutjanus argentiventris) in the Gulf of California. Mar Biol 156:2461-2472. https://doi. org/10.1007/s00227-009-1271-5

Aburto-Oropeza O, Erisman B, Galland GR, Mascarenas-Osorio I, Sala E, Ezcurra E (2011) Large recovery of fish biomass in a no-take marine reserve. PLoS ONE 6:e23601. https://doi.org/10.1371/journal.pone.0023601.t001

Ainsworth $\mathrm{CH}$ et al (2011) Atlantis model development for the northern Gulf of California. U.S. Department of Commerce, National Oceanic and Atmospheric Administration. NOAA Technical Memorandum NMFS-NWFSC-110

Airame S, Dugan JE, Lafferty KD, Leslie H, McArdle D, Warner RR (2003) Applying ecological criteria to marine reserve design: a case study from the California Channel islands. Ecol Appl 13:S170-S184

Alvarez-Borrego S (2010) Physical, chemical and biological oceanography of the Gulf of California. In: Brusca RC (ed) The Gulf of California: biodiversity and conservation. The University of Arizona Press, Tucson, pp 22-48

Alvarez-Romero JG, Pressey RL, Ban NC, Torre-Cosio J, Aburto-Oropeza O (2013) Marine conservation planning in practice: lessons learned from the Gulf of California. Aquat Conserv Mar Freshw Ecosyst 23:483-505. https://doi.org/ 10.1002/aqc. 2334

Alvarez-Romero JG, Pressey RL, Ban NC, Brodie J (2015) Advancing land-sea conservation planning: integrating modelling of catchments, land-use change, and river plumes to prioritise catchment management and protection. PLoS ONE 10:e0145574. https://doi.org/10.1371/journal. pone. 0145574

Alvarez-Romero JG et al (2018) Designing connected marine reserves in the face of global warming. Glob Change Biol 24:e671-e691. https://doi.org/10.1111/gcb.13989

Anadon JD, Mancha-Cisneros MM, Best BD, Gerber LR (2013) Habitat specific larval dispersal and marine connectivity: implications for spatial conservation planning. Ecosphere 4:Article 82:81-115. https://doi.org/10.1890/es13-00119.1

Ayala-Bocos A, Reyes-Bonilla H, Calderón-Aguilera LE, Herrero-Perezrul MD, González-Espinosa PC (2016) 
Proyección de cambios en la temperatura superficial del mar del Golfo de California y efectos sobre la abundancia y distribución de especies arrecifales. Rev Cienc Mar Costeras 8:29-40. https://doi.org/10.15359/revmar.8-1.2

Baskett ML, Barnett LAK (2015) The ecological and evolutionary consequences of marine reserves. Ann Rev Ecol Evol Syst 46:49-73. https://doi.org/10.1146/annurevecolsys-112414-054424

Beger $\mathrm{M}$ et al (2015) Integrating regional conservation priorities for multiple objectives into national policy. Nat Commun 6:8208. https://doi.org/10.1038/ncomms9208

Bennett NJ (2018) Navigating a just and inclusive path towards sustainable oceans. Mar Policy. https://doi.org/10.1016/j. marpol.2018.06.001

Bennett NJ, Lasch-Thaler C, Mancha-Cisneros MM, SuarezCastillo AN, Walther-Mendoza M, Vazquez-Vera L, Espinosa-Romero MJ (2017) Integración de consideraciones socio-económicas y de gobernanza en el diseño y manejo de las zonas de recuperación en el Golfo de California, México. The Nature Conservancy/Comunidad y Biodiversidad A.C., La Paz

Botsford LW, Hastings A, Gaines SD (2001) Dependence of sustainability on the configuration of marine reserves and larval dispersal distance. Ecol Lett 4:144-150

Botsford LW, Micheli F, Hastings A (2003) Principles for the design of marine reserves. Ecol Appl 13:S25-S31

Botsford LW et al (2009) Connectivity, sustainability, and yield: bridging the gap between conventional fisheries management and marine protected areas. Rev Fish Biol Fish 19:69-95. https://doi.org/10.1007/s11160-008-9092-z

Botsford LW, White JW, Carr MH, Caselle FE (2014) Marine protected area networks in California, USA. In: Johnson ML, Sandell J (eds) Advances in marine biology, vol 69. Academic Press, Oxford, pp 205-251

Brock RJ, Kenchington E, Martínez-Arroyo A (2012) Scientific guidelines for designing resilient marine protected area networks in a changing climate. Commission for Environmental Cooperation, Montreal, Canada, $95 \mathrm{pp}$

Brusca RC, Hendrickx ME (2010) Invertebrate biodiversity and conservation in the Gulf of California. In: Brusca RC (ed) The Gulf of California biodiversity and conservation. The University of Arizona Press, Tucson, pp 72-95

Brusca RC, Findley LT, Hastings PA, Hendrickx ME, TorreCosio J, Heiden VDAM (2005) Macrofaunal diversity in the Gulf of California. In: Cartron J, Ceballos G, Felger RS (eds) Biodiversity, ecosystems and conservation in Northern Mexico. Oxford University Press, New York, pp 179-202

Carvajal MA, Robles A, Ezcurra E (2010) Ecological conservation in the Gulf of California. In: Brusca RC (ed) The Gulf of California biodiversity and conservation. The University of Arizona Press, Tucson, pp 219-250

Caselle JE, Rassweiler A, Hamilton SL, Warner RR (2015) Recovery trajectories of kelp forest animals are rapid yet spatially variable across a network of temperate marine protected areas. Sci Rep 5:14102. https://doi.org/10.1038/ srep14102

Cavole L et al (2016) Biological impacts of the 2013-2015 warm-water anomaly in the Northeast Pacific: winners, losers, and the future. Oceanography. https://doi.org/10. 5670/oceanog. 2016.32
Ceballos-Vázquez BP, Elorduy-Garay JF (1998) Gonadal development and spawning of the golden-eyed tilefish Caulolatilus affinis (Pisces: Branchiostegidae) in the Gulf of California, Mexico. Bull Mar Sci 63:469-479

Cisneros-Mata MA (2010) The importance of fisheries in the Gulf of California and ecosystem-based sustainable comanagement for conservation. In: Brusca RC (ed) The Gulf of California biodiversity and conservation. The University of Arizona Press, Tucson, pp 119-134

Cisneros-Montemayor AM, Cisneros-Mata MA, Harper S, Pauly D (2013) Extent and implications of IUU catch in Mexico's marine fisheries. Mar Policy 39:283-288. https:// doi.org/10.1016/j.marpol.2012.12.003

Cowen RK, Sponaugle S (2009) Larval dispersal and marine population connectivity. Ann Rev Mar Sci 1:443-466. https://doi.org/10.1146/annurev.marine.010908.163757

Cubero-Pardo P, Donovan C, Urbán-Ramírez J (2011) A proposal to define vulnerability of cetacean areas to human development: variables and analysis procedures applied to the Gulf of California. Aqua Conserv Mar Freshw Ecosyst 21:433-447. https://doi.org/10.1002/aqc.1205

Cudney-Bueno R, Lavin MF, Marinone SG, Raimondi PT, Shaw WW (2009) Rapid effects of marine reserves via larval dispersal. PLoS ONE 4:e4140. https://doi.org/10. 1371/journal.pone.0004140.g001

Dolby GA, Bennett SEK, Lira-Noriega A, Wilder BT, MunguiaVega A (2015) Assessing the geological and climatic forcing of biodiversity and evolution surrounding the Gulf of California. J Southwest 57:391-455

Doney SC et al (2012) Climate change impacts on marine ecosystems. Ann Rev Mar Sci 4:11-37. https://doi.org/10. 1146/annurev-marine-041911-111611

Dudley NE (2008) Guidelines for applying protected area management categories. Gland, Switzerland

Edgar GJ et al (2014) Global conservation outcomes depend on marine protected areas with five key features. Nature 506:216-220. https://doi.org/10.1038/nature13022

Elith J, Phillips S, Hastie T, Dudik M, Chee YE, Yates C (2011) A statistical explanation of MaxEnt for ecologists. Divers Distrib 17:43-57

Erisman B, Mascarenas I, Paredes G, Sadovy de Mitcheson Y, Aburto-Oropeza O, Hastings P (2010) Seasonal, annual, and long-term trends in commercial fisheries for aggregating reef fishes in the Gulf of California, Mexico. Fish Res 106:279-288. https://doi.org/10.1016/j.fishres.2010. 08.007

Erisman B, Aburto-Oropeza O, Gonzalez-Abraham C, Mascareñas-Osorio I, Moreno-Báez M, Hastings PA (2012) Spatio-temporal dynamics of a fish spawning aggregation and its fishery in the Gulf of California. Sci Rep 2:1-11. https://doi.org/10.1038/srep00284

Erisman B, Heyman W, Kobara S, Ezer T, Pittman S, AburtoOropeza O, Nemeth RS (2017) Fish spawning aggregations: where well-placed management actions can yield big benefits for fisheries and conservation. Fish Fish 18:128-144. https://doi.org/10.1111/faf.12132

Fernandes L et al (2005) Establishing representative no-take areas in the Great Barrier Reef: large-scale implementation of theory on marine protected areas. Conserv Biol 19:1733-1744. https://doi.org/10.1111/j.1523-1739.2005. 00302.x 
Fogarty MJ, Botsford LW (2007) Population connectivity and spatial management of marine fishes. Oceanography 20:112-123

Fraschetti S, D'Ambrosio P, Micheli F, Pizzolante F, Bussotti S, Terlizzi A (2009) Design of marine protected areas in a human-dominated seascape. Mar Ecol Prog Ser 375:13-24. https://doi.org/10.3354/meps07781

Froese R, Demirel N, Coro G, Kleisner KM, Winker H (2017) Estimating fisheries reference points from catch and resilience. Fish Fish 18:506-526. https://doi.org/10.1111/faf. 12190

Gaines SD, White C, Carr MH, Palumbi SR (2010) Designing marine reserve networks for both conservation and fisheries management. Proc Natl Acad Sci USA 107:18286-18293. https://doi.org/10.1073/pnas. 0906473107

Gerber LR, Mancha-Cisneros MDM, O'Connor MI, Selig ER (2014) Climate change impacts on connectivity in the ocean: implications for conservation. Ecosphere 5:art33. https://doi.org/10.1890/es13-00336.1

Gill DA et al (2017) Capacity shortfalls hinder the performance of marine protected areas globally. Nature 543:665-669. https://doi.org/10.1038/nature21708

Gilly WF, Zeidberg LD, Booth JA, Stewart JS, Marshall G, Abernathy K, Bell LE (2012) Locomotion and behavior of Humboldt squid, Dosidicus gigas, in relation to natural hypoxia in the Gulf of California, Mexico. J Exp Biol 215:3175-3190. https://doi.org/10.1242/jeb.072538

Gonzalez-Abraham C, Ezcurra E, Garcillan PP, Ortega-Rubio A, Kolb M, Bezaury Creel JE (2015) The human footprint in Mexico: physical geography and historical legacies. PLoS ONE 10:e0121203. https://doi.org/10.1371/journal. pone. 0121203

Green A et al (2009) Designing a resilient network of marine protected areas for Kimbe Bay, Papua New Guinea. Oryx 43:488. https://doi.org/10.1017/s0030605309990342

Green AL et al (2014) Designing marine reserves for fisheries management, biodiversity conservation, and climate change adaptation. Coast Manag 42:143-159. https://doi. org/10.1080/08920753.2014.877763

Green AL et al (2015) Larval dispersal and movement patterns of coral reef fishes, and implications for marine reserve network design. Biol Rev Camb Philos Soc 90:1215-1247. https://doi.org/10.1111/brv.12155

Halpern BS et al (2008) A global map of human impact on marine ecosystems. Science 319:948-952. https://doi.org/ 10.1126/science. 1149345

Halpern BS et al (2015) Spatial and temporal changes in cumulative human impacts on the world's ocean. Nat Commun 6:7615. https://doi.org/10.1038/ncomms8615

Haro-Martinez AA, Parra-Salazar IE, Licon-Gonzalez HA (2000) Desarrollo de la metodología de amenazas potenciales a nivel ecorregional: el Golfo de California. Reporte Tecnico de CECARENA A WWF, Guaymas, Mexico

Hastings PA, Findley LT, Van der Heiden AMV (2010) Fishes of the Gulf of California. In: Brusca RC (ed) The Gulf of California. Biodiversity and conservation. The University of Arizona Press, Tucson, pp 96-118

Hinojosa-Arango G, Rioja-Nieto R, Suárez-Castillo ÁN, Riosmena-Rodríguez R (2014) Using GIS methods to evaluate rhodolith and Sargassum beds as critical habitats for commercially important marine species in Bahía Concepción, B.C.S., México. Cryptogam Algol 35:49-65. https://doi.org/10.7872/crya.v35.iss1.2014.49

Hooker SK, Cañadas A, Hyrenbach KD, Corrigan C, Polovina JJ, Reeves RR (2011) Making protected area networks effective for marine top predators. Endanger Species Res 13:203-218. https://doi.org/10.3354/esr00322

Hopkins CR, Bailey DM, Potts T (2016) Perceptions of practitioners: managing marine protected areas for climate change resilience. Ocean Coast Manag 128:18-28. https:// doi.org/10.1016/j.ocecoaman.2016.04.014

IPCC (2013) The physical science basis. In: Stocker T et al (eds) Contribution of working group I to the fifth assessment report of the Intergovernmental Panel on Climate Change. Cambridge University Press, New York

Jessen S et al (2011) Science-based guidelines for MPAs and MPA networks in Canada. Canadian Parks and Wilderness Society, Vancouver

Johnson AF, Moreno-Baez M, Giron-Nava A, Corominas J, Erisman B, Ezcurra E, Aburto-Oropeza O (2017) A spatial method to calculate small-scale fisheries effort in data poor scenarios. PLoS ONE 12:e0174064. https://doi.org/10. 1371/journal.pone.0174064

Krueck NC et al (2018) Reserve sizes needed to protect coral reef fishes. Conserv Lett 11:e12415. https://doi.org/10. 1111/conl.12415

Lavin M, Marinone SG (2003) An overview of the physical oceanography of the Gulf of California. In: VelascoFuentes OU, Sheinbaum J, Ochoa de la Torre JL (eds) Nonlinear processes in geophysical fluid dynamics. Kluwer, Dordrecht, pp 173-204

Lluch-Cota SE, Tripp-Valdez M, Lluch-Cota DB, BautistaRomero JJ, Lluch-Belda D, Verbesselt J, Herrera-Cervantes H (2013) Recent trends in sea surface temperature off Mexico. Atmósfera 26:537-546. https://doi.org/10.1016/ s0187-6236(13)71094-4

Lodeiros C et al (2016) Spondylids of eastern pacific ocean. J Shellfish Res 35:279-293. https://doi.org/10.2983/035. 035.0203

MacNeil MA et al (2015) Recovery potential of the world's coral reef fishes. Nature 520:341-344. https://doi.org/10. 1038 /nature 14358

Marinone SG (2012) Seasonal surface connectivity in the Gulf of California. Estuar Coast Shelf Sci 100:133-141. https:// doi.org/10.1016/j.ecss.2012.01.003

Marinone SG, Lavín MF, Parés-Sierra A (2011) A quantitative characterization of the seasonal lagrangian circulation of the Gulf of California from a three-dimensional numerical model. Cont Shelf Res 31:1420-1426. https://doi.org/10. 1016/j.csr.2011.05.014

McLeod E, Salm R, Green A, Almany J (2009) Designing marine protected area networks to address the impacts of climate change. Front Ecol Environ 7:362-370. https://doi. org/10.1890/070211

McLeod E et al (2012) Integrating climate and ocean change vulnerability into conservation planning. Coast Manag 40:651-672. https://doi.org/10.1080/08920753.2012. 728123

Morzaria-Luna H (2016) Determinación de la extensión y situación actual de reservas marinas en la Región de las Grandes Islas (RGI) y Norte del Golfo de California para 
reducir los efectos del cambio climático en la producción pesquera y la función del ecosistema. CEDO Intercultural. Programa de las Naciones Unidas para el Desarrollo (PNUD). Comisión Nacional de Áreas Naturales Protegidas (CONANP), Tucson, USA

Morzaria-Luna H, Turk-Boyer P, Moreno-Baez M (2014) Social indicators of vulnerability for fishing communities in the Northern Gulf of California, Mexico: implications for climate change. Mar Policy 45:182-193. https://doi.org/10. 1016/j.marpol.2013.10.013i

Munguia-Vega A et al (2014) Asymmetric connectivity of spawning aggregations of a commercially important marine fish using a multidisciplinary approach. PeerJ 2:e511

Munguia-Vega A, Leyva-Valencia I, Lluch-Cota DB, CruzHernández P (2015a) Genetic structure of cortes geoduck clam Panopea globosa Dall 1898 from the Mexican Northwest. J Shellfish Res 34:153-161. https://doi.org/10. 2983/035.034.0100

Munguia-Vega A et al (2015b) PANGAS: an interdisciplinary ecosystem-based research framework for small-scale fisheries in the Northern Gulf of California. J Southwest 57:337-390

Munguia-Vega A et al (2018) Anisotropic larval connectivity and metapopulation structure driven by directional oceanic currents in a marine fish targeted by small-scale fisheries. Mar Biol. https://doi.org/10.1007/s00227-017-3267-x

Olsen E et al (2018) Ocean futures under ocean acidification, marine protection, and changing fishing pressures explored using a worldwide suite of ecosystem models. Front Mar Sci 5:64. https://doi.org/10.3389/fmars.2018.00064

Paez-Osuna F et al (2016) Environmental status of the Gulf of California: a review of responses to climate change and climate variability. Earth Sci Rev 162:253-268. https://doi. org/10.1016/j.earscirev.2016.09.015

Palumbi SR (2004) Marine reserves and ocean neighborhoods: the spatial scale of marine populations and their management. Ann Rev Environ Resour 29:31-68. https://doi.org/ 10.1146/annurev.energy.29.062403.102254

Raedig C, Dormann CF, Hildebrandt A, Lautenbach S (2010) Reassessing neotropical angiosperm distribution patterns based on monographic data: a geometric interpolation approach. Biodivers Conserv 19:1523-1546. https://doi. org/10.1007/s10531-010-9785-1

Reyes-Bonilla H, Carriquiry J, Leyte-Morales G, Cupul-Magana A (2002) Effects of the El Nino-Southern Oscillation and the anti-El Nino event (1997-1999) on coral reefs of the western coast of Mexico. Coral Reefs 21:368-372

Rife AN, Erisman B, Sanchez A, Aburto-Oropeza O (2013) When good intentions are not enough ... Insights on networks of "paper park" marine protected areas. Conserv Lett 6:200-212. https://doi.org/10.1111/j.1755-263X. 2012.00303.x

Riginos C (2005) Cryptic vicariance in Gulf of California fishes parallels vicariant patterns found in Baja California mammals and reptiles. Evolution 59:2678-2690

Roberts CM et al (2002) Marine biodiversity hotspots and conservation priorities for tropical reefs. Science 295:1280-1284. https://doi.org/10.1126/science.1067728

Roberts CM et al (2003) Application of ecological criteria in selecting marine reserves and developing reserve networks. Ecol Appl 13:215-228
Roberts CM et al (2017) Marine reserves can mitigate and promote adaptation to climate change. Proc Natl Acad Sci USA 114:6167-6175. https://doi.org/10.1073/pnas. 1701262114

Saarman E et al (2013) The role of science in supporting marine protected area network planning and design in California. Ocean Coast Manag 74:45-56. https://doi.org/10.1016/j. ocecoaman.2012.08.021

Sadovy MY, Erisman B (2012) Fishery and biological implications of fishing spawning aggregations, and the social and economic importance of aggregating fishes. In: Sadovy de Mitcheson Y, Colin PL (eds) Reef fish spawning aggregations: 225 biology, research and management, pp 225-284. https://doi.org/10.1007/978-94-007-1980-4_8

Sagarin RD, Gilly WF, Baxter CH, Burnett N, Christensen J (2008) Remembering the Gulf: changes to the marine communities of the Sea of Cortez since the Steinbeck and Ricketts expedition of 1940. Front Ecol Environ 6:374-381

Sala E, Aburto-Oropeza O, Paredes G, Parra I, Barrera JC, Dayton PK (2002) A general model for designing networks of marine reserves. Science 298:1991-1993. https://doi. org/10.1126/science. 1075284

Sala E, Aburto-Oropeza O, Paredes G, Thompson G (2003) Spawning aggregations and reproductive behavior of reef fishes in the Gulf of California. Bull Mar Sci 72:103-121

Sala E, Aburto-Oropeza O, Reza M, Paredes G, López-Lemus LG (2004) Fishing down coastal food webs in the Gulf of California. Fisheries 29:19-25. https://doi.org/10.1577/ 1548-8446(2004)29[19:fdcfwi]2.0.co;2

Sale PF et al (2010) Preserving reef connectivity; a handbook for marine protected area managers. Connectivity Working Group, Coral Reef Targeted Research \& Capacity Building for Management Program, UNU-INWEH., Melbourne, Australia

Soria G, Munguía-Vega A, Marinone SG, Moreno-Báez M, Martínez-Tovar I, Cudney-Bueno R (2012) Linking biooceanography and population genetics to assess larval connectivity. Mar Ecol Prog Ser 463:159-175. https://doi. org/10.3354/meps09866

Soria G, Torre-Cosio J, Munguia-Vega A, Marinone SG, Lavín MF, Cinti A, Moreno-Báez M (2014) Dynamic connectivity patterns from an insular marine protected area in the Gulf of California. J Mar Syst 129:248-258. https://doi. org/10.1016/j.jmarsys.2013.06.012

Soto CG (2002) The potential impacts of global climate change on marine protected areas. Rev Fish Biol Fish 11:181-195

Spalding MD et al (2007) Marine ecoregions of the world: a bioregionalization of coastal and shelf areas. Bioscience 57:573-583

Spalding MD, Brumbaugh RD, Landis E (2016) Atlas of Ocean Wealth. Arlington, VA

Suarez-Castillo AN et al (2014) Valoración económica de los servicios ecosistémicos de los bosques de Sargassum en el Golfo de California, México. In: Urciaga-Garcia JI (ed) Desarrollo Regional en Baja California Sur: Una Perspectiva de los Servicios Ecosistémicos. Universidad Autonoma de Baja California Sur, La Paz, pp 79-111

Turk-Boyer P, Morzaria-Luna H, Martinez-Tovar I, DowntonHoffmann C, Munguia-Vega A (2014) Ecosystem-based fisheries management of a biological corridor along the Northern Sonora coastline (NE Gulf of California). In: 
Amezcua F, Bellgraph B (eds) Fisheries management of Mexican and central American Estuaries, Estuaries of the world. Springer, New York, pp 125-154

Ulate K, Sánchez C, Sánchez-Rodríguez A, Alonso D, AburtoOropeza O, Huato-Soberanis L (2016) Latitudinal regionalization of epibenthic macroinvertebrate communities on rocky reefs in the Gulf of California. Mar Biol Res 12:389-401. https://doi.org/10.1080/17451000.2016. 1143105
Watson JR, Kendall BE, Siegel DA, Mitarai S (2012) Changing seascapes, stochastic connectivity, and marine metapopulation dynamics. Am Nat 180:99-112. https://doi.org/10. 1086/665992

WCS, CIESIN (2005) Last of the wild project, version 2, (LWP2): Global human footprint dataset (IGHP). NASA Socioeconomic Data and Applications Center (SEDAC), Palisades, NY 